\title{
Skill mismatch and use in developed countries: Evidence from the PIAAC study
}

Citation for published version (APA):

Allen, J. P., Levels, M., \& van der Velden, R. K. W. (2013). Skill mismatch and use in developed countries: Evidence from the PIAAC study. Maastricht University, Graduate School of Business and Economics. GSBE Research Memoranda No. 061 https://doi.org/10.26481/umagsb.2013061

Document status and date:

Published: 01/01/2013

DOI:

10.26481/umagsb.2013061

Document Version:

Publisher's PDF, also known as Version of record

\section{Please check the document version of this publication:}

- A submitted manuscript is the version of the article upon submission and before peer-review. There can be important differences between the submitted version and the official published version of record.

People interested in the research are advised to contact the author for the final version of the publication, or visit the DOI to the publisher's website.

- The final author version and the galley proof are versions of the publication after peer review.

- The final published version features the final layout of the paper including the volume, issue and page numbers.

Link to publication

\footnotetext{
General rights rights.

- You may freely distribute the URL identifying the publication in the public portal. please follow below link for the End User Agreement:

www.umlib.nl/taverne-license

Take down policy

If you believe that this document breaches copyright please contact us at:

repository@maastrichtuniversity.nl

providing details and we will investigate your claim.
}

Copyright and moral rights for the publications made accessible in the public portal are retained by the authors and/or other copyright owners and it is a condition of accessing publications that users recognise and abide by the legal requirements associated with these

- Users may download and print one copy of any publication from the public portal for the purpose of private study or research.

- You may not further distribute the material or use it for any profit-making activity or commercial gain

If the publication is distributed under the terms of Article $25 \mathrm{fa}$ of the Dutch Copyright Act, indicated by the "Taverne" license above, 


\section{Maastricht University}

J im Allen, Mark Levels, Rolf van der Velden

Skill mismatch and use in developed countries: evidence from the PIAAC study

RM/13/061

\section{GSBE}

Maastricht University School of Business and Economics

Graduate School of Business and Economics

P.O Box 616

NL-6200 MD Maastricht

The Netherlands 


\section{Skill mismatch and skill use in developed countries: evidence from the PIAAC study ${ }^{1}$}

Jim Allen*, Mark Levels and Rolf van der Velden

\section{Abstract}

In this paper we develop and test a new set of measures of skill mismatches, based on data on skill levels and skill use in the domains of literacy and numeracy from the PIAAC project. The measures we develop represent the extent of skill use relative to one's own skill level. We test the measures by examining their relation to a number of labour market outcomes. We subsequently examine how mismatches are distributed across and within a large number of countries, and use our results to reflect on possible causes and consequences of mismatches. We find that, in general, higher skill utilization is always beneficial in terms of productivity and job satisfaction, and that "overutilization" of skills therefore points more towards a fuller use of the available human capital, rather than to a serious skill shortage. We find an asymmetry in returns between literacy and numeracy skills: although numeracy skill level appears to pay higher dividends than literacy skill level, shifts in skill utilization within skill levels have greater consequences for literacy than for numeracy. The distribution of mismatches across and within countries is broadly consistent with the expectation that skills will be used more fully under competitive market conditions with few institutional or organizational barriers. Finally, skill mismatches are only quite weakly related to educational mismatches, reflecting the heterogeneity in skill supply and demand that cross-cuts the dividing lines set by formally defined qualification levels and job titles.

JEL classification: 121, 125, J23, J24

Keywords: education, labour market, skills, skill utilization

* Corresponding author

\section{Introduction}

The paper aims to provide a major contribution to the ongoing debate on mismatches in the labour market and their effects. In the past this debate has focused out of necessity mainly on educational mismatches (e.g. Duncan and Hoffman, 1981; Sicherman, 1991; Green, McIntosh and Vignoles, 1999; Groot and Maassen van den Brink, 2000; Hartog, 2000; Sloane, 2003), supplemented by simple self-

\footnotetext{
${ }^{1}$ The authors wish to thank Martin Humburg and Jaap Dronkers for their helpful comments on an earlier version of this paper.
} 
reports by workers on their skill mismatches (e.g. Allen and van der Velden, 2001; Green and McIntosh, 2007). In this paper we develop and test a new measure that identifies skill mismatches directly, based on data on skill levels and skill use in the domains of literacy and numeracy from the PIAAC project. Using this measure, we look at possible causes of mismatches, their distribution across and within countries, and their relationships with a number of labour market outcomes.

As a recent overview article by Quintini (2011) makes clear, there has been a large amount of research into labour market mismatches in recent decades (see e.g. Allen and Van der Velden 2001, Green and MacIntosh 2007). Although different researchers have defined mismatches in a wide variety of ways, there are some underlying common elements that most, if not all, of the studies share. The most obvious common feature is the perception that the primary justification for studying mismatches is the belief that mismatches have serious consequences for the performance, productivity and rewards of workers who experience them. This is not to say that all researchers studying mismatches share this belief in equal measure, only that the debate about their importance is the major motivating factor in most, if not all, mismatch research (Sloane, 2003; Leuven and Oosterbeek 2011).

A second feature that the diverse studies of mismatches share is the (sometimes implicit) understanding that the phenomenon of mismatch is at its core driven by heterogeneity in the labour market. It is understood that there is heterogeneity both in supply - the diverse qualifications, skills, experiences and the like of those who offer their services to potential employers - and in demand the qualifications, skills and experiences required to perform the tasks at hand. However, although this understanding is more or less universal, it is not always made explicit which assumptions the researchers are making with respect to the existing heterogeneity on both sides. Most of the differences between the various definitions of mismatches can be traced to differences in these assumptions.

In the case of educational mismatches, the relevant assumption is that both individuals and jobs can be meaningfully grouped in terms of qualification levels possessed and required. Within each qualification level, individuals and jobs are essentially treated as equivalent. Although strictly speaking this is obviously highly unrealistic, this does not render the study of educational mismatches meaningless. Especially for young people, true productivity is often imperfectly observable, which means that selection, allocation and wage rates are often quite heavily based on qualifications and formal job descriptions, with the latter often containing a specification of the qualifications required. It is also plausible that education and job levels are quite strongly related to skills possessed and 
required, and these expectations have received considerable support from empirical research results.

Even so, this still leaves many questions unanswered, such as the extent to which actual skills and skill requirements vary within these broad categories, and the extent to which individuals who are "mismatched" in terms of their education are sorted according to this heterogeneity on both the supply and the demand side of the labour market. If "overeducated" workers - that is people working in a job nominally requiring a lower level of education than their own - have lower skills than "well-matched" workers, they may not be mismatched at all in terms of skills. The same would apply if the actual skill requirements of the jobs of overeducated workers are similar to those for jobs nominally requiring the level of education that the worker possesses. The opposite but otherwise equivalent rationale could apply to "undereducated" workers. As has been pointed out, such a scenario can account for the observed effects of educational mismatches on outcomes as well as the mooted effects of skill underutilization and skill shortages that are claimed to be associated with educational mismatches. It is this possibility that has led many skeptics to question the extent to which educational mismatches are a real problem. This is the main reason why the focus of the debate has shifted increasingly from educational mismatches to skill mismatches in recent years.

This research has been hindered by a relative lack of data on heterogeneity on both the supply and demand sides. There has been some data available on the supply side - the skill levels of workers mainly coming from large-scale projects such as IALS and ALL, of which PIAAC forms the latest contribution. However, to date, there is no comparable measure on the demand side, in which the level of skill required for the job is measured on an equivalent or comparable metric. As a result, we still find ourselves in a situation in which literal skill mismatches cannot be directly measured.

There is no prospect that this problem will be solved in the foreseeable future, at least with respect to measuring mismatches on a scale sufficient to make statements as to their incidence and possible causes and effects on the level of national labour markets as a whole. Likely solutions would all require some form of analysis of people's actual jobs, which could only be done in the workplace. It would also be highly challenging to say the least to distinguish job requirements from people's actual performance in the job, which would be a hybrid measure of skills and skill requirements. This difficulty notwithstanding, it might possibly be achievable to measure skill mismatches in small scale studies involving a limited number of firms, but would be very difficult to extend this to the national level, which is what is needed for any serious analysis of the extent and consequences of mismatches. 
If we want to study skill mismatches, we are therefore left with the alternative option of seeking measures that can be used to proxy skill requirements or skill mismatches. The simplest of these involve a subjective assessment by workers of the extent to which their skills match the requirements of their job (see e.g. Allen and van der Velden 2001). Such studies have in fact been found to yield interesting and largely plausible results. However, the subjective nature of such measures renders them vulnerable to criticism, for example on the grounds that workers may not possess all the information that is needed for a balanced assessment, or that they might exaggerate their own abilities and/or the requirements of their job.

An objective alternative that has been used in recent years (e.g. OECD 2013a) is to create a proxy for skill requirements based on the skills typically possessed by people working in the same occupation as the respondent who regard themselves as well-matched. However, as we will explain in more detail below, this method gives rise to some serious methodological issues that can be shown to seriously bias the results. The main point is that, while it considers the full range of heterogeneity on the supply side, it reduces the heterogeneity on the demand side to a small number of occupational categories. This ignores the fact that, within those occupational categories, skill levels can be shown to strongly covary with skill requirements. This leads to some rather paradoxical outcomes, such as the finding that the group of workers who are identified as underutilized within an occupational category are, on average, the group with the highest skill requirements.

In this paper, we also use a proxy for skill requirements, namely the extent of skill use, as measured through skill use scales based on self-reported frequency. Such a method has been considered and rejected by other researchers, on the grounds that frequency of skill use is something quite different from required level (OECD 2013a). While we concede that this is strictly speaking true, we would argue that the seriousness of this problem has been exaggerated, and that, if applied and interpreted with appropriate caution, skill mismatch measures based on this approach yield valid results, and provide highly valuable insights. To begin with, as we will show below, there is in fact strong empirical evidence that skill use is quite strongly related to required skill level. Additionally, skill use and skill mismatches derived by using skill use in combination with skill level - show clear and plausible relationships with labour market outcomes. Finally, even if one strictly adheres to the claim that skill use scales such as provided in the PIAAC data are exclusively measures of frequency of skill use, and not at all of level of skill use, efficiency considerations dictate that the greatest productivity is achieved when the people with the highest level of a given skill in the population are the ones who 
are using that skill the most often, and that the least skilled are those that use that skill the least often.

Strictly speaking, the measure we employ in this paper is a measure of skill use relative to one's own skill level. According to this indicator, an individual is well-matched when one's skill use falls within a range that is usual for a person with a comparable skill level. Mismatched workers are those individuals whose skill use is unusually high or low with respect to what one would expect, given their skill level. Although we don't make any strong a priori claims as to the extent to which mismatches as we define them are necessarily related to shortages and/or surpluses in the sense of having a lower or higher level than required in the job, we believe that a strong case can be made, based on the empirical results obtained, that this is at least to some extent the case.

Ultimately we view this as an empirical rather than a conceptual issue. In our view the results we present in this paper clearly support the view that underutilization is frequently associated with skill surpluses. It is less clear from our results that overutilization points to serious skill shortages. The results rather suggest that an unusually high level of skill use relative to one's own skill level points to what might be termed supermatching: a situation in which the available skills are almost fully used. Interestingly, this is largely consistent with research findings with respect to both undereducation and subjective overutilization, which suggest that labour market returns are higher for people working "above their own level" either in terms of education or skills.

In fact, this is entirely consistent with the view of heterogeneous supply and demand in the labour market as the basis for mismatches. The notion that there is a qualification or skill requirement level that is most commonly associated with workers at each given skill or qualification level does not dictate that this "match" has to occur at a point in which skills or qualifications are being fully used. In fact, it is more plausible to expect that "well-matched" workers are working within their own capacities to some extent, and are capable of improving their performance if given the opportunity to work at a higher level. In this view, being undereducated or overutilized reflects a job that is, up to a point at least, challenging, satisfying and rewarding. A similar effect may be supposed to occur in the case of overeducated or underutilized workers, but this time with the better educated or more skilled worker being more productive than less skilled (well-matched) workers working at the same job level, because they more fully exploit the productive potential of the job.

Our aim in this paper is twofold. Firstly, we aim to validate our measure, by examining its relation to a number of labour market outcomes. After validating our measure in this manner, we will pursue 
the second aim of this paper, namely to identify countries, and specific subgroups of workers within those countries, who are currently using their skills more or less than one would expect based on their skill level. Before preceding to these analyses, in the next section we describe the data used and provide a description of the variables used in the analyses. We will then give a detailed account of our chosen measure of mismatch, and explain why we have chosen these over possible alternative measures.

\section{Description of data/variables}

\subsection{PIAAC dataset}

For our analyses we use data from the Programme for the International Assessment of Adult Competencies [PIAAC], collected by the OECD (2013b) in a large number of developed countries. We use data from 22 countries, namely Austria, Belgium (Flanders), Canada, Cyprus, the Czech Republic, Denmark, Estonia, Finland, France, Germany, Ireland, Italy, Japan, South Korea, the Netherlands, Norway, Poland, the Slovak Republic, Spain, Sweden, the United Kingdom (England and Northern Ireland) and the United States. The survey is designed to provide valid and reliable estimates of adults' competences in key information-processing skills, to identify proficiency differences between sub-groups of the population, to understand development, maintenance and use of skills, as well as to determine the impact of proficiency levels on life chances (OECD, 2013c). The samples per country each comprise at least 5000 adults between the age of 16 and 65. Respondents were interviewed using a combination of computer assisted personal interviews, although pencil-and-paper data collection strategies were also used. Respondents were given assessment tests designed to directly measure their numerical and literacy skills, as well as respondents' capacity to solve problems in technology-rich environments. The dataset also contains information on respondents' skills use in the work place, as well as an extensive set of background variables concerning among other things educational attainment, current employment status, job characteristics, socio-economic background and personal characteristics. We restricted the analyses to individuals who were in paid employment at the time of the survey, and whose current main status was not "student" or "apprentice/intern". ${ }^{2}$

2. The exclusion of students is necessary because student jobs are often low-skilled temporary jobs taken for the sole purpose of helping the individual or his/her family pay for the expense of obtaining an education. Apprenticeships and internships are excluded because they are not purely work, but a combination of education and work. We used subjective status rather than the objective indicator for those currently in formal education, because we did not wish to exclude working respondents who are enrolled in part-time education but whose main activity is paid work. 
Missing values in the regression analyses were deleted listwise. The working file contains $N=100,110$ respondents.

\subsection{Skills and skill mismatch indicators}

The PIAAC dataset provides measures of three types of skills, namely literacy skills, numeracy skills, and skills related to problem solving in technology-rich environments (OECD, 2013c). Skill scales in all three domains have been constructed using adaptive testing and plausible values are calculated using Item Response Theory (IRT). In this paper we do not use the data on problem solving in technology rich environments, primarily because, in contrast to the other two skill domains, there were no comparable scales on skill use for this domain. Skill use was narrowed to use of ICT-skills, which is only part of the broader domain problem solving in technology-rich environments. Additionally, the tests in this domain were only presented to people who reported that they had at least some computer experience, were willing to take the computer-based assessment and had at least minimum levels of computer abilities. Including these tests would non-randomly reduce our sample size by almost $33 \%$.

The OECD (2013c) defines literacy as "the ability to understand, evaluate, use and engage with written texts to participate in society, to achieve one's goals, and to develop one's knowledge and potential. Literacy encompasses a range of skills from the decoding of written words and sentences to the comprehension, interpretation, and evaluation of complex texts." Similarly, numeracy is defined as "the ability to access, use, interpret and communicate mathematical information and ideas in order to engage in and manage the mathematical demands of a range of situations in adult life." The tests of numeracy measure how well respondents are able to use mathematical information to solve problems that might actually occur in real life. Both numeracy and literacy are measured with 10 plausible values.

The method used to derive skill mismatches as used in this paper is very simple.

1. We restrict the analysis to respondents who are currently in paid employment, and who do not describe their own current status as "Pupil, student" or "Apprentice, internship".

2. For this restricted group, we standardize the relevant measure of skill level and skill use (that is, compute the z-score) for the skill domains of literacy and numeracy: 
a. For skill level we take the first plausible value of each skill measure; ${ }^{3}$

b. We construct a scale consisting of the mean of the seven reading use items and four writing use items included in the background questionnaire to indicate literacy use. For numeracy use we construct a scale consisting of the mean of the six numeracy use items included in the background questionnaire. ${ }^{4}$

3. We subtract each standardized measure of skill use from the corresponding standardized measure of skill level.

4. We define all individuals with a value of no more than 1.5 points above or below zero on this difference variable as "well-matched". We define all individuals with a value less than -1.5 as "overutilized", and all individuals with a value greater than 1.5 as "underutilized". ${ }^{5}$

\subsection{Other variables used in the analyses}

In the Section 4 we use the relation with three outcome (dependent) variables to validate our mismatch measure:

- Hourly wage (In): the natural logarithm of the hourly earnings reported by workers, PPP converted into US dollars. To avoid possible distortion due to outliers, the highest and lowest $1 \%$ of observed earnings have been removed.

- Job satisfaction: Answer on a 5-point scale to the question "All things considered, how satisfied are you with your current job?" Response categories range from 1 "Extremely dissatisfied" to 5 "Extremely dissatisfied". Comparable results are obtained based on a dichotomized variable distinguishing satisfied workers (responses 4 and 5) and non-satisfied workers (responses 1, 2 and 3).

- Training participation: respondents who reported having participated in at least one form of non-formal education in the last 12 months are assigned the value 1. Respondents who report not having participated in non-formal education in that period are assigned the value 0.

3. Because we need to identify skill mismatches uniquely, we cannot perform the analyses in this paper using the full range of plausible values. All analyses have also been run using the mean of the 10 plausible values, which only leads to minor changes in the results. These additional results are available from the authors on request.

4. See below for a detailed discussion of the properties of these scales and our reasons for preferring them over the existing scales included in the dataset.

5. Because the component scales were standardized, 1.5 points on the mismatch scales means 1.5 standard deviations on either component scale. This means that, for example, an underutilized worker displays a degree of skill use that is 1.5 standard deviations lower than his/her skill level. 
In these analyses we control for the effects of a number of other characteristics. Some of these also function as independent variables in the analyses predicting skill mismatches.

- Highest completed education: based on international ISCED classification, distinguishing the following categories: ISCED1+2, ISCED 3, ISCED4, ISCED5B, ISCED5A bachelor programmes, ISCED 5A master programmes or doctorate.

- Educational mismatches: based on highest completed education and self-reported level of education that someone applying for the respondent's job would need if applying today. Both measures were converted into nominal years of schooling required to attain that level, and a difference score is calculated. Those whose own years of schooling exceed the years of schooling required for the job are classed as overeducated. Those whose own years of schooling are less than the years of schooling required for the job are classed as undereducated. Those whose years of schooling are equal to those required are classed as well-matched.

- Gender: female (reference category male)

- Age in categories, starting with $16-19$, followed by 5-year groupings for older respondents

- Ethnicity: respondents born in the host country are classed as native, with a further distinction being made between immigrants from western versus non-western countries. Due to a relatively large number of missing values for this variable, a missing dummy has also been included.

- Occupational level, based on 1-digit ISCO code, distinguishing 4 levels: skilled occupations (ISCO1-3), semi-skilled white-collar occupations (ISCO4-5), semi-skilled blue-collar occupations (ISCO6-8), and elementary occupations (ISCO9).

- Sector: public/non-profit versus private sector

- Firm size in 4 categories: 1-10, 11-50, 51-1000, 1001 or more.

- VET: indicator derived for those with secondary education based on national coding of highest attained education. The indicator distinguishes vocational from general education.

\section{Explaining our choice of mismatch indicators}

As mentioned in the introduction, in this paper we use a very particular set of indicators for mismatch in this paper, which are quite different from those preferred and used by other researchers. For example, researchers from the OECD (2013a) have criticized the use of such a scale, 
preferring an alternative methodology, which we will discuss below. The essence of their criticism of a measure based on a comparison of skill level and skills use is twofold. Firstly, they claim that such a measure rests on the assumption that the two are measured on the same scale, an assumption that clearly does not hold in this case. Secondly, they point out that skills proficiency and skills use as measured in the PIAAC project are substantively too different to make any comparison of the two meaningful. These are serious points, and in addition to these there are also other more detailed points that could be raised that could potentially invalidate the measure we use. As it is necessary in order to establish that the results we present are meaningful to establish that the scales we use are valid, at least within well-defined limits, we look at these issues in some detail.

To start first with the second point raised by the OECD, we happily concede that skill level and skill use as measured in the PIAAC project are substantively different. Skill level is based on the results of information processing tests, whereas skill use is based on self-reported frequency of performance of a set of well-defined activities relevant to the skill domain in question. In fact this substantive difference is only a problem if we claim that we are measuring mismatches strictly in terms of shortages and surpluses. As stated in the introduction, our measure is strictly speaking a measure of skill use in relation to skill level. The extent to which this reflects actual mismatches, in the sense of shortages or surpluses, is in our view as much an empirical question as a theoretical one. It is not even necessary for the purposes of our paper to resolve this issue definitively, since we will interpret all the results presented in terms of the measure as so defined, namely as skill use relative to skill level. This is in itself relevant information, both in scientific terms and for policy purposes.

The first point raised by the OECD is potentially more serious. This point states that the metrics along which skills and skill use are measured are fundamentally different, making it impossible to construct a relative measure combining the two. If the two metrics fail to mesh up properly, there is no way of knowing which level on one metric equates with a given level on the other, which would mean that there is no way of identifying where workers stop being overutilized and start being underutilized. However, once again, when we define our measure as one of skill use relative skill level, this criticism loses most of its sting. It is no longer necessary that the two mesh up perfectly, because a higher or a lower score simply means that skill use is higher or lower than one would normally expect for a worker with that level of skills. And because we restrict ourselves to fairly extreme mismatches (corresponding to 1.5 standard deviations above or below the "expected" skill use for a given skill level), we can be fairly confident that workers who are identified as mismatched indeed have a level of skill use that is unusually high or low for workers with a comparable skill level. 
There is however also the issue of possible non-linearity in the relationship, which could give rise to spurious mismatches in certain parts of the skills continuum. Although the restriction to extreme mismatches largely removes the risk of completely erroneous mismatches, serious non-linearities can give rise to higher or lower proportions of mismatched respondents in certain sub-populations that are the spurious result of the method used to derive the measures. As Figure 1 shows however, skill use is very nearly linear in skill level, with just a slight concavity for literacy and a slight convexity for numeracy.

Figure 1: Mean and 95\% confidence interval of score on skill use scales by rounded plausible value 1 on equivalent skill level scale, all countries (pooled data)
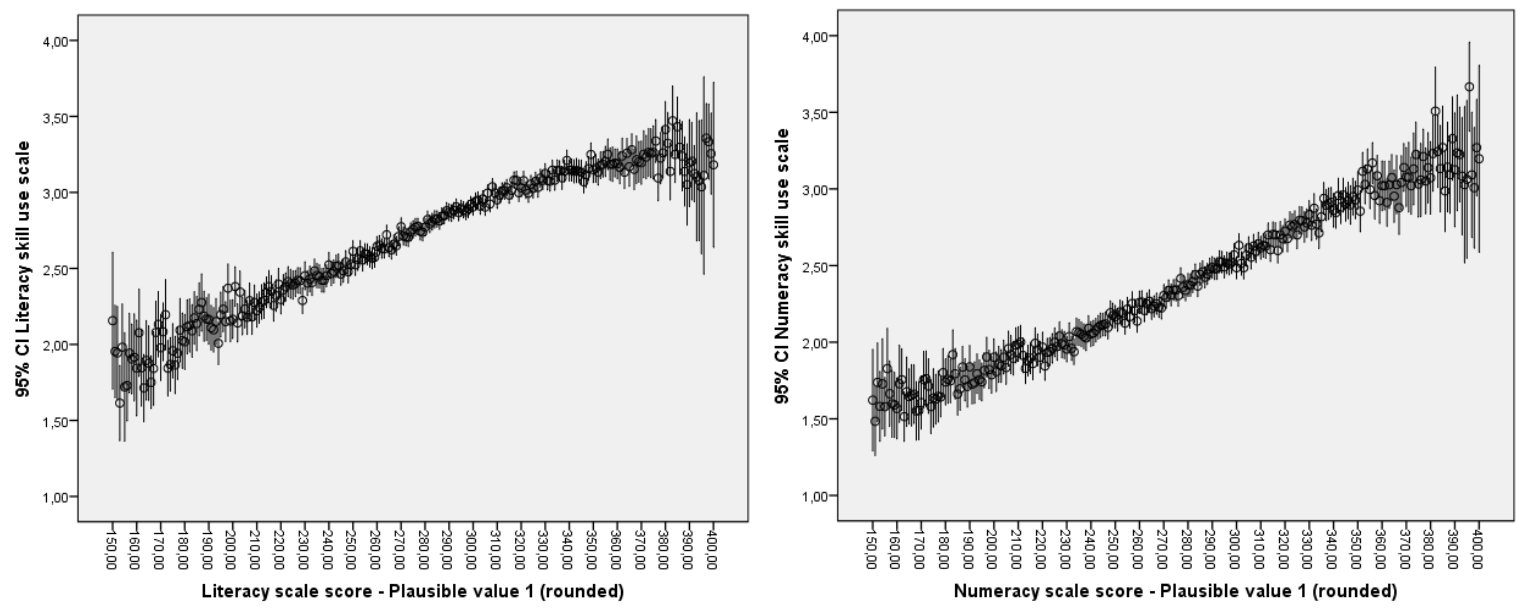

In short, as long as we keep in mind the precise meaning of our mismatch measures when analyzing and interpreting the data, the points raised by the OECD do not invalidate the measures. There are however a number of other points that can be raised and which should be discussed as well.

To begin with, our decision to construct the measures based on pooled data from in total 22 countries, rather than separately per country, presupposes that they are effectively objective measures that are comparable across countries. For skill level we believe that this criterion can be assumed to be met, since the provision of such internationally comparable measures is the raison d'etre for the PIAAC project. We believe that the criterion of comparability also applies to skill use, although this is less obviously true than is the case for skill level. The assumption of objectivity is not strictly true for the skill use scales: they are based on self-reported frequencies. However, because the skill use scales are based on the reported frequency of a set of clearly defined and internationally fully comparable activities, the only seriously plausible source of bias is that due to consciously or unconsciously misleading answers. There is no reason to expect any such bias to be systematic across 
countries or other units of interest. ${ }^{6}$ If we assume that both skill level and skill use scales are internationally comparable, it is not only legitimate to construct our measures using pooled data, but entirely appropriate. This allows us to compare countries and identify those which have relatively high or low levels of skill use relative to the skill level of their working populations.

Our measure also presupposes that the simple skill use scales we construct, based on the simple mean of the underlying items, are valid. The main reason for constructing our own scales rather than using the available scale variables in the PIAAC database is that the latter scales have been constructed after omitting the "all zero responses", that is, respondents who reported a frequency of "never" on all items. The reason for doing so seems to be to have because in this way the literacy and numeracy use scales are comparable to the ICT use scales, which were only asked of respondents who reported using a computer at work. However, we argue that this creates serious bias in the skill use measure, by omitting the category of workers with the lowest possible level of use, namely none at all. A second reason for constructing our own scales is the fact that the "official" scales separate reading and writing use, both of which seem to be relevant for the overarching skill dimension of literacy. $^{7}$

We could have converted the items into actual frequencies before scaling, but argue that the existing 5-point scale is in fact more appropriate. It is in fact a very close approximation of a log scale, which makes more sense when comparing respondents who give different answers. The more frequently a worker performs an activity, the less heavily an additional performance of that activity will weigh in terms of its "effect" on productivity. This is by no means an obvious point, because it rests on the assumption that the activities described in skill use items are not in themselves the primary drivers of productivity (in which case each additional performance should be comparably productive), but serve as proxies for different types of work that are more or less literacy/numeracy-intensive. In other words, it is assumed that when a worker who reads or writes a large number of e-mails at work, it is not so much the volume e-mails of itself which drives productivity, but what this large number of email exchanges says about the requirements of the job in terms of the general use of literacy skills. We believe that this is a realistic assumption.

6. It is relevant in this context to point out that all background information on respondents who participated in the PIAAC survey, including for example their current occupation, is based on self-reports, and is therefore similarly subject to potential bias.

7. We have conducted several checks to ensure that our simple scales are valid, for example by checking that they correlate strongly with the "official" scales, both within and between countries. This is indeed the case (results of these analyses are available from the authors on request). 
Finally we should make a couple of remarks that are relevant to the interpretation of our results rather than the validity of the scales. First of all, there is the question of the extent to which skill use, which is strictly speaking a measure of frequency, also reflects to some extent difference in the level at which skills are applied. The fact that there is a rather strong correlation between skill level and skill use could be evidence that this is the case, although this is quite weak. Even for highly educated workers there is a significant correlation in most countries between skill level and a restricted skill use scale based on items thought to reflect skill use requiring only a low proficiency level. This is consistent with the common sense notion that workers who are good at performing some task will be more likely to do so, regardless of the level at which the task is performed. In fact, the best evidence that the skill use scales may have a level component is the fact that the underlying items appear to differ in the level of proficiency required. Individuals with a high score must almost of necessity have scored highly on items requiring a high proficiency. Nonetheless, we feel it is more appropriate to view these scales as reflecting mainly frequency or intensity of use, and only secondarily level of proficiency required. For that reasons, our skill mismatch measures should be interpreted primarily as measures of a higher or lower intensity of use than is usual for workers at that skill level.

Finally, it should be noted that our measures have been constructed in such a way that overall supply of and demand for skills is assumed to be perfectly balanced in the aggregate, i.e. has the same overall mean and standard deviation. We are therefore only able to identify relative shortages and surpluses. For this reason, we have rather arbitrarily chosen the cut-off points at 1.5 points above or below the overall mean, which coincidentally corresponds very closely to $10 \%$ of the population being mismatched at both ends of the continuum.

Although we have now given a thorough account of the method we use in this paper, we should also explain why we prefer this over available alternatives. An obvious choice of alternative would be an occupation-based approach such as used by the OECD (2013a). This is a modification of the method developed by Verdugo and Verdugo (1989) for calculating educational mismatches. The method used to construct this measure is as follows. Firstly they identify people who they call "self-reported wellmatched" workers. These are people who answer "no" to two questions included in the PIAAC background questionnaire, namely "Do you feel that you have the skills to cope with more demanding duties than those you are required to perform in your current job?" and "Do you feel that you need further training in order to cope well with your present duties?". They then look at the distribution of skill proficiency scores for this restricted group, per country and 1 digit occupation code (ISCO-2008). Because of sample size limitations, they are forced to merge ISCO codes 1 
(Managers) and 2 (Professionals), and to drop ISCO codes 0 (Armed Forces) and 6 (Skilled Agricultural Workers). They define workers who score within the range of the $5^{\text {th }}$ to the $95^{\text {th }}$ percentile on this distribution as "well-matched". Workers who score below the $5^{\text {th }}$ percentile are classed as "overutilized", while workers who score above the $95^{\text {th }}$ percentile are classed as "underutilized".

We reject this measure on both methodological and empirical grounds. The main methodological objection to this measure rests on its assumption that skill requirements are uniform within occupations. ${ }^{8}$ Even using an extremely detailed occupational classification this assumption would be problematic. Coding errors inevitably occur, and these are generally more severe for a detailed classification. More importantly, we may expect employers to adjust their skill requirements for a given job to the skill set of the job occupant. This means that, say, a very good accountant is using a different skill set than a less competent accountant. When we add to this the heterogeneity in skill requirements that inevitably occurs when we are forced to use a less detailed classification (recall that we are forced to use 1-digit codes(!) due to insufficient cell size at a more detailed level), and it becomes obvious that a large amount of what is classed as mismatches in fact reflects skill heterogeneity within occupational categories. As Figure 2 makes clear, this heterogeneity is very strongly related to skill use.

Figure 2: Literacy skill use by skill level by 1-digit occupation ${ }^{9}$

8. A legitimate objection can also be raised to the questions used to identify "self-reported well-matched" workers. Over $80 \%$ of workers report that they could cope with more demanding duties, which means that only $20 \%$ are "well-matched" according to this criterion alone. More than a quarter of all workers answer "yes" to both questions, making them simultaneously "underutilized" and "overutilized". In practice however, these objections do not turn out to matter much, since the $5^{\text {th }}-95^{\text {th }}$ percentile ranges defined based on the restricted group are not systematically different from those based on the full sample. In other words, the measure could just as well have been constructed without the restriction.

9. A similar picture applies for numeracy. 


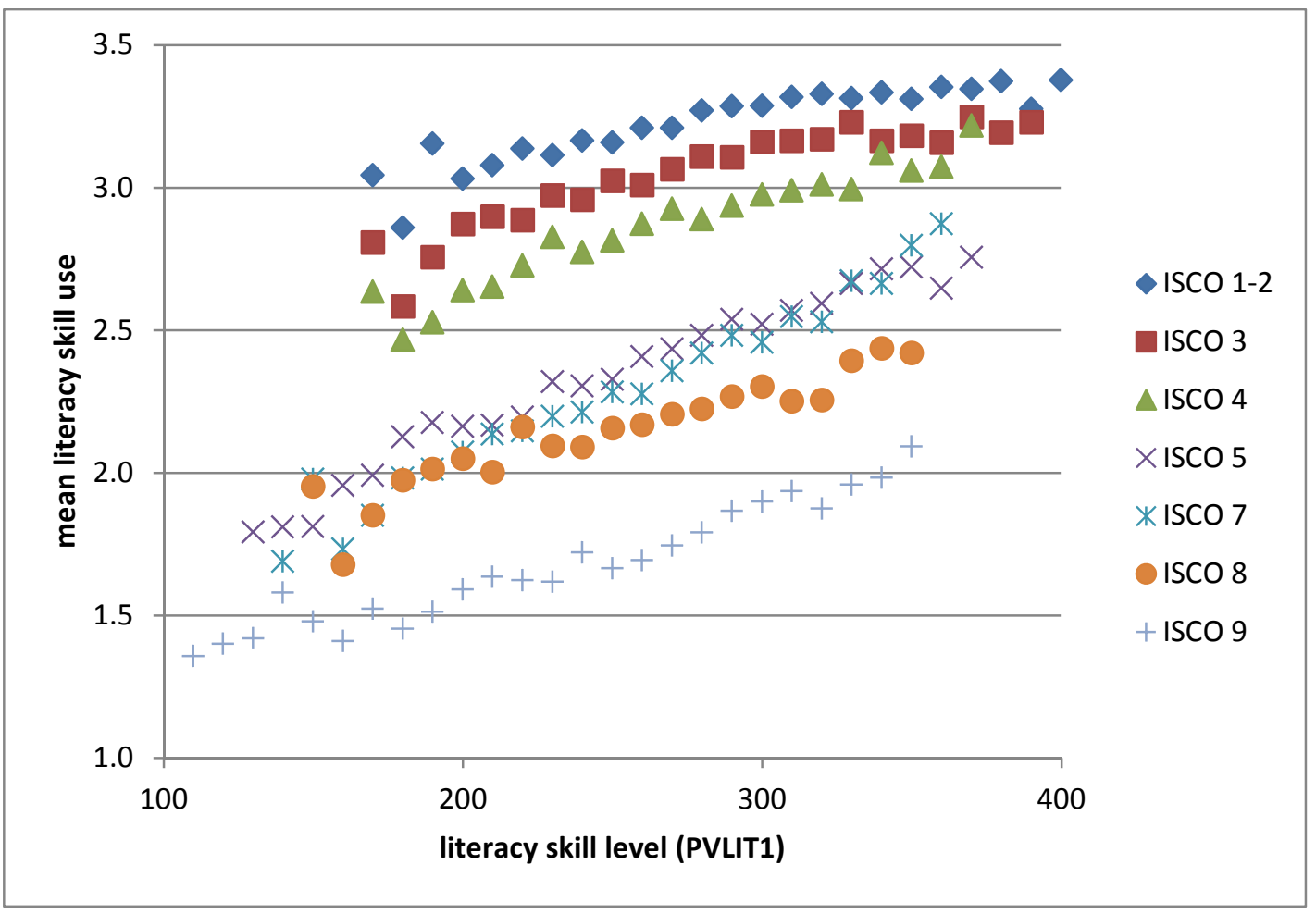

Even if we accept the OECD's point that the metrics of skills and skill use are not strictly comparable, such covariance between them within broad occupational categories cannot be ignored. It stretches credibility beyond breaking point to suggest that such a strong relationship exists between skill level and skill use, but that no relationship exists between skill level possessed by workers and the required skill level for their job. This creates a huge problem for the OECD mismatch measure. Recall that the method dictates that mismatches are constituted by the tails of the skills distribution within occupations, precisely where skill use shows a corresponding high or low level respectively. It is not even obvious that these individuals are any more mismatched than those in the middle of the distribution per occupation. This feature of the OECD measure leads to striking anomalies, such as the finding, within the 1 digit code representing Managers and Professionals (ISCO codes 1 and 2), 2digit occupational sub-categories representing occupational fields that are known to be cognitively very demanding, such as science and engineering professionals and information and communications technology professionals, are relatively often classed as heavily "underutilized", whereas mid-level managers, who belong to the same broad occupational class, are much more often classed as "overutilized".

Although perhaps necessary when using this methodology, it can be argued that calculating mismatches separately by country also distorts the results. Since the skill level corresponding to a given occupational group is very different across countries, this has the consequence that, say, a 
manager or professional in a low skill country will be more likely to be underutilized and less likely to be overutilized than an equally skilled manager or professional in a high-skill country. To the extent that skill requirements associated with given occupation also differ accordingly across countries, ${ }^{10}$ this could be "correct", but it can paint a highly misleading and counterintuitive picture unless people are aware of the relative nature of this definition. Intuitively, we would expect low-skill countries to be more prone to overutilization and less prone to underutilization. Due to this feature of the OECD measure, the opposite is more nearly true. High skill countries like Sweden and Finland are supposedly relatively overutilized, whereas low skill countries like Spain and Italy are heavily underutilized. This is directly analogous to the situation we saw above for occupations.

For the remainder of this paper we present only results based on our own measure of skills mismatch, combining skill levels and skill use measures. However, all the analyses presented have been conducted using the OECD measure as well as our own. With the exception of the very different pattern that is observed across countries, occupations and economic sectors, the results based on this measure are broadly similar, but almost without exception weaker. The full results based on the OECD measure are available from the authors on request.

\section{Relation between skill mismatches and outcomes}

Before proceeding to describe the distribution of mismatches both between and within countries, it is important to validate our measure, by examining its relation to a number of labour market outcomes. We look at three measures in this section: earnings, job satisfaction, and the propensity to engage in training.

Both on theoretical grounds, and based on prior research into educational mismatches and subjective measures of skills mismatch, we expect underutilization to be related to lower wages, and overutilization to higher wages, after controlling for one's own skill level. In general, the wage penalty associated with underutilization is found to be smaller than the wage premium associated with overutilization. This asymmetry is usually explained in terms of job assignment theory. Those working in jobs below their level are assumed to be thereby prevented from using a substantial part of their productive skills, hence the large drop in earnings. Those working in matching jobs are often assumed to already be using a large proportion of their skills, although as remarked above, not all by

10. This is only partially the case. In general skill levels differ more strongly across countries than across occupations, whereas skill use shows the opposite pattern. As a consequence, a worker in a low-skill country is even more likely to be overutilized than a comparably skilled worker in a similar occupation in a high skill country. 
any means. As the level of the job increases, one's own skill increasing becomes a limiting factor putting a ceiling on productivity and hence earnings. There is a premium, but of limited size.

Underutilization is also generally found to lower job satisfaction, and the theoretical justification that is normally given for this is quite straight-forward: people gain satisfaction from using the skills they have acquire in school, at work and through other life experiences, and are frustrated when they find themselves in a job which provides limited scope for them to do so. The expectation for overutilization is less straight forward. On one hand, we might expect people to experience overutilization of their skills as stressful, because they are being asked to perform tasks that are too demanding for them. In that case, we might expect overutilization to be related to lower job satisfaction. However, if we accept that "well-matched" workers are not fully using their skills, we might expect that increasing the extent to which they use their skills to increase their satisfaction, at least up to a point. Prior research (see e.g. Allen and Van der Velden, 2001) seems to indicate that this is indeed the case. Again, both the theory and such prior research indicates that this effect is smaller than the negative effect of underutilization. ${ }^{11}$

There is a potential circularity in terms of the possible effects of mismatch on training. On one hand, we would expect training to be undertaken more often when the existing skills are being overutilized, and less often when they are already being underutilized. At the same time, training would presumably be designed to reduce skill mismatches, which would indicate the opposite relation. However, there seems to be a growing consensus that regular training is an endemic feature of dynamic jobs in which new shortages arise to replace the old ones as soon as they are eliminated (Allen and de Grip, 2012). We would therefore expect overutilization to be related to a higher propensity to engage in training, while underutilization is expected to be related to a lower training propensity.

In this section we look at the relation of skill mismatches according to our measure with these outcome measures. All analyses contain controls for occupational level, broad economic sector (private versus public/non-profit), age, gender, ethnicity, highest completed education and own skill level in both domains. The relationships between mismatches in terms of literacy and numeracy on one hand and each of the outcome on the other are estimated simultaneously. Only relationships that are statistically significant at $5 \%$ level are shown in the graphs.

11. We also observe that, in all participating countries, well over three quarters of all workers whose skills are overutilized in their work report that they have the skills to cope with more demanding duties than they are currently performing. This proportion is hardly different from that for well-matched and underutilized workers. 
The relation with earnings

Table 1 shows the relation of skill mismatches with the natural logarithm of hourly wage. The estimates are consistent and frequently quite large, especially for literacy mismatches. On average across all participating countries, we see that literacy underutilization is associated with a wage penalty of around $11 \%$, and overutilization with a wage premium of around $7 \%$. The corresponding figures for numeracy amount to around $4 \%$ and $5 \%$ respectively. There is considerable variation between countries, and sometimes individual relationships do not attain significance, but in no case is a significant relationship in the opposite direction observed.

Table 1: Relation between skill mismatches and In(Earnings)

\begin{tabular}{|c|c|c|c|c|c|c|c|c|c|c|c|c|}
\hline \multirow{2}{*}{$\begin{array}{l}\text { In(earnings) } \\
\text { Country }\end{array}$} & \multicolumn{3}{|c|}{ Literacy underutilization } & \multicolumn{3}{|c|}{$\begin{array}{c}\text { Literacy } \\
\text { overutilization }\end{array}$} & \multicolumn{3}{|c|}{$\begin{array}{c}\text { Numeracy } \\
\text { underutilization }\end{array}$} & \multicolumn{3}{|c|}{$\begin{array}{c}\text { Numeracy } \\
\text { overutilization }\end{array}$} \\
\hline & $B$ & & S.E. & $\mathrm{B}$ & & S.E. & $\mathrm{B}$ & & S.E. & $\mathrm{B}$ & & S.E. \\
\hline Austria & -0.120 & $* * *$ & 0.030 & 0.084 & $* * *$ & 0.028 & -0.061 & $* * *$ & 0.021 & 0.085 & $* *$ & 0.040 \\
\hline Belgium & -0.061 & $* * *$ & 0.020 & 0.039 & & 0.033 & -0.013 & & 0.015 & -0.022 & & 0.039 \\
\hline Canada & -0.122 & $* * *$ & 0.022 & 0.048 & $* *$ & 0.019 & -0.012 & & 0.023 & 0.061 & $* * *$ & 0.020 \\
\hline Cyprus & -0.065 & & 0.042 & 0.034 & & 0.038 & 0.015 & & 0.032 & 0.072 & & 0.047 \\
\hline Czech Republic & -0.204 & $* * *$ & 0.036 & 0.064 & & 0.103 & -0.011 & & 0.029 & 0.094 & $*$ & 0.051 \\
\hline Denmark & -0.070 & $* * *$ & 0.027 & 0.058 & & 0.037 & -0.058 & $* * *$ & 0.015 & 0.070 & & 0.089 \\
\hline Estonia & -0.135 & $* * *$ & 0.025 & 0.129 & $* * *$ & 0.034 & -0.074 & $* * *$ & 0.027 & 0.027 & & 0.031 \\
\hline Finland & -0.069 & $* * *$ & 0.016 & 0.048 & $*$ & 0.028 & -0.038 & $* *$ & 0.018 & 0.036 & & 0.030 \\
\hline \multicolumn{13}{|l|}{ France* } \\
\hline Germany & -0.153 & $* * *$ & 0.044 & 0.106 & $* * *$ & 0.031 & -0.080 & $* * *$ & 0.028 & 0.010 & & 0.049 \\
\hline Ireland & -0.144 & $* * *$ & 0.042 & 0.163 & $* * *$ & 0.045 & -0.152 & $* * *$ & 0.058 & -0.041 & & 0.082 \\
\hline Italy & -0.124 & $* * *$ & 0.030 & 0.091 & $*$ & 0.048 & 0.017 & & 0.034 & -0.029 & & 0.059 \\
\hline Japan & -0.108 & $* * *$ & 0.038 & 0.160 & $* * *$ & 0.058 & -0.015 & & 0.029 & 0.096 & $*$ & 0.054 \\
\hline Korea & -0.168 & $* *$ & 0.071 & 0.092 & $*$ & 0.053 & -0.055 & & 0.049 & 0.136 & $* * *$ & 0.048 \\
\hline Netherlands & -0.081 & $* * *$ & 0.020 & 0.000 & & 0.075 & -0.018 & & 0.018 & 0.021 & & 0.054 \\
\hline Norway & -0.070 & $*$ & 0.039 & 0.028 & & 0.032 & -0.045 & $* * *$ & 0.016 & 0.068 & $*$ & 0.041 \\
\hline Poland & -0.095 & $* * *$ & 0.028 & 0.083 & $*$ & 0.048 & -0.002 & & 0.036 & 0.120 & $* * *$ & 0.046 \\
\hline Slovak Republic & -0.086 & $* * *$ & 0.031 & 0.114 & & 0.100 & -0.043 & & 0.029 & 0.056 & & 0.056 \\
\hline Spain & -0.077 & $* * *$ & 0.026 & 0.094 & $* * *$ & 0.036 & 0.028 & & 0.036 & 0.027 & & 0.028 \\
\hline Sweden & -0.029 & & 0.018 & 0.044 & & 0.027 & -0.041 & $* * *$ & 0.015 & 0.021 & & 0.033 \\
\hline United Kingdom & -0.096 & $* * *$ & 0.028 & 0.075 & $* * *$ & 0.027 & -0.036 & & 0.030 & 0.093 & $* * *$ & 0.028 \\
\hline United States & -0.127 & $* * *$ & 0.045 & 0.004 & & 0.032 & -0.093 & $* *$ & 0.038 & 0.102 & $* * *$ & 0.032 \\
\hline Int. Avg. & -0.105 & $* * *$ & 0.008 & 0.074 & $* * *$ & 0.011 & -0.037 & $* * *$ & 0.007 & 0.053 & $* * *$ & 0.011 \\
\hline
\end{tabular}

The relation with job satisfaction 
Table 2 shows the relation between skill mismatches and job satisfaction. The relationships are not quite as strong as those observed for wage, but nonetheless consistent, and again largest for literacy mismatches. On average across all participating countries, we see that literacy underutilization is associated with a drop of around 0.13 points on the 5 -point scale, and overutilization with an increase of around 0.12 points. The corresponding relationships for numeracy are small and nonsignificant across all countries, although significant relationships are observed in several countries, which are generally small and sometimes in the opposite direction. This suggests that there is no systematic relation between numeracy mismatches and satisfaction once literacy mismatches have been taken into account.

Table 2: Relation between skill mismatches and job satisfaction

\begin{tabular}{|c|c|c|c|c|c|c|c|c|c|c|c|c|}
\hline \multirow{2}{*}{$\begin{array}{l}\text { Job satisfaction } \\
\text { Country }\end{array}$} & \multicolumn{3}{|c|}{$\begin{array}{c}\text { Literacy } \\
\text { underutilization }\end{array}$} & \multicolumn{3}{|c|}{$\begin{array}{c}\text { Literacy } \\
\text { overutilization }\end{array}$} & \multicolumn{3}{|c|}{$\begin{array}{c}\text { Numeracy } \\
\text { underutilization }\end{array}$} & \multicolumn{3}{|c|}{ Numeracy overutilization } \\
\hline & $\mathrm{B}$ & & S.E. & $\mathrm{B}$ & & S.E. & $\mathrm{B}$ & & S.E. & B & & S.E. \\
\hline Austria & -0.059 & & 0.078 & 0.011 & & 0.049 & -0.046 & & 0.051 & -0.012 & & 0.086 \\
\hline Belgium & -0.148 & $* *$ & 0.060 & 0.035 & & 0.086 & 0.010 & & 0.044 & -0.094 & & 0.103 \\
\hline Canada & -0.226 & $* * *$ & 0.058 & 0.118 & $* * *$ & 0.040 & 0.074 & $*$ & 0.040 & -0.013 & & 0.040 \\
\hline Cyprus & -0.064 & & 0.071 & 0.030 & & 0.079 & -0.036 & & 0.055 & 0.059 & & 0.075 \\
\hline Czech Republic & -0.103 & & 0.067 & 0.212 & $* *$ & 0.099 & 0.087 & & 0.131 & -0.148 & $*$ & 0.085 \\
\hline Denmark & -0.081 & & 0.058 & 0.061 & & 0.043 & -0.087 & $* *$ & 0.038 & 0.127 & $*$ & 0.071 \\
\hline Estonia & -0.063 & & 0.047 & 0.066 & & 0.048 & -0.051 & & 0.041 & 0.018 & & 0.058 \\
\hline Finland & -0.061 & & 0.040 & 0.076 & & 0.080 & -0.059 & & 0.052 & 0.033 & & 0.081 \\
\hline France & -0.185 & $* * *$ & 0.049 & 0.099 & $*$ & 0.053 & -0.025 & & 0.048 & -0.033 & & 0.050 \\
\hline Germany & -0.075 & & 0.072 & 0.084 & & 0.071 & -0.028 & & 0.054 & -0.007 & & 0.082 \\
\hline Ireland & -0.094 & & 0.076 & 0.048 & & 0.068 & 0.054 & & 0.071 & -0.033 & & 0.078 \\
\hline Italy & -0.220 & $* *$ & 0.090 & 0.055 & & 0.085 & 0.019 & & 0.087 & -0.099 & & 0.096 \\
\hline Japan & -0.050 & & 0.049 & 0.210 & $* *$ & 0.094 & -0.002 & & 0.049 & -0.023 & & 0.131 \\
\hline Korea & -0.066 & & 0.063 & 0.223 & $* * *$ & 0.053 & 0.024 & & 0.062 & 0.042 & & 0.066 \\
\hline Netherlands & -0.205 & $* * *$ & 0.055 & 0.096 & & 0.066 & -0.053 & & 0.037 & 0.014 & & 0.097 \\
\hline Norway & -0.039 & & 0.065 & 0.162 & $* * *$ & 0.054 & -0.113 & $* *$ & 0.044 & -0.076 & & 0.085 \\
\hline Poland & -0.127 & $* *$ & 0.052 & 0.145 & & 0.089 & 0.040 & & 0.063 & 0.008 & & 0.067 \\
\hline Slovak Republic & -0.190 & $* * *$ & 0.052 & 0.179 & $* *$ & 0.084 & 0.010 & & 0.042 & 0.096 & & 0.085 \\
\hline Spain & -0.192 & $* *$ & 0.080 & 0.165 & $* *$ & 0.067 & 0.005 & & 0.075 & -0.092 & & 0.063 \\
\hline Sweden & -0.143 & $* *$ & 0.062 & 0.293 & $* * *$ & 0.086 & -0.048 & & 0.056 & -0.216 & & 0.157 \\
\hline United Kingdom & -0.242 & $* *$ & 0.097 & 0.126 & $*$ & 0.069 & 0.147 & $* *$ & 0.063 & -0.065 & & 0.094 \\
\hline United States & -0.224 & $* * *$ & 0.075 & 0.057 & & 0.063 & -0.271 & $* * *$ & 0.097 & 0.072 & & 0.050 \\
\hline Int. Avg. & -0.130 & $* * *$ & 0.014 & 0.116 & $* * *$ & 0.015 & -0.016 & & 0.013 & -0.020 & & 0.018 \\
\hline
\end{tabular}

The relation with training participation 
Table 3 shows the relation between skill mismatches on training participation. Again, the literacy coefficients are dominant, showing a consistent pattern of decreased participation for the underutilized, and increased participation for the overutilized. The coefficients are slightly stronger overall for underutilization - a $16 \%$ decrease in participation - than for overutilization - a $14 \%$ increase. The corresponding shifts due to numeracy mismatches are much smaller, $3 \%$ and $4 \%$ respectively. All significant coefficients are in the expected direction.

Table 3: Relation between skill mismatches and training participation

\begin{tabular}{|c|c|c|c|c|c|c|c|c|c|c|c|c|}
\hline \multirow{2}{*}{$\begin{array}{l}\text { Training participation } \\
\text { Country }\end{array}$} & \multicolumn{3}{|c|}{ Literacy underutilization } & \multicolumn{3}{|c|}{$\begin{array}{c}\text { Literacy } \\
\text { overutilization }\end{array}$} & \multicolumn{3}{|c|}{$\begin{array}{c}\text { Numeracy } \\
\text { underutilization }\end{array}$} & \multicolumn{3}{|c|}{$\begin{array}{c}\text { Numeracy } \\
\text { overutilization }\end{array}$} \\
\hline & B & & S.E. & B & & S.E. & $\mathrm{B}$ & & S.E. & $\mathrm{B}$ & & S.E. \\
\hline Belgium & -16.214 & $* * *$ & 4.101 & 23.744 & $* * *$ & 4.860 & -7.400 & $* * *$ & 2.210 & 1.434 & & 6.111 \\
\hline Canada & -18.637 & $* * *$ & 3.167 & 15.089 & $* * *$ & 2.436 & -5.450 & $* *$ & 2.701 & 3.104 & & 2.527 \\
\hline Denmark & -28.239 & $* * *$ & 5.469 & 17.503 & $* * *$ & 2.894 & -0.417 & & 1.904 & 4.447 & & 4.353 \\
\hline Estonia & -15.682 & $* * *$ & 3.744 & 14.594 & $* * *$ & 3.503 & -1.961 & & 2.379 & -0.122 & & 3.130 \\
\hline Finland & -10.118 & $* * *$ & 2.373 & 11.317 & $* * *$ & 4.100 & -6.081 & $* *$ & 2.590 & -2.747 & & 4.257 \\
\hline France & -20.372 & $* * *$ & 2.951 & 16.052 & $* * *$ & 2.637 & 2.698 & & 2.797 & 3.359 & & 2.770 \\
\hline Japan & -18.337 & $* * *$ & 4.410 & 26.456 & $* * *$ & 5.274 & -0.356 & & 3.026 & 4.122 & & 5.070 \\
\hline Korea & -8.486 & $* *$ & 2.944 & 11.628 & $* * *$ & 3.039 & -2.833 & & 3.151 & 9.608 & $* * *$ & 3.218 \\
\hline Netherlands & -11.030 & $* * *$ & 3.761 & 17.668 & $* * *$ & 3.663 & -3.732 & & 2.470 & 3.739 & & 6.092 \\
\hline Norway & -13.245 & $* * *$ & 2.846 & 11.270 & $* * *$ & 4.065 & -4.608 & & 3.031 & 1.014 & & 5.635 \\
\hline Poland & -17.295 & $* * *$ & 3.974 & 13.774 & $* * *$ & 4.834 & -7.965 & $* *$ & 3.781 & 9.280 & $* *$ & 4.013 \\
\hline Slovak Republic & -16.022 & $* * *$ & 2.674 & 13.984 & $* * *$ & 5.237 & -6.889 & $* *$ & 3.155 & 9.862 & $* *$ & 4.561 \\
\hline Spain & -16.995 & $* * *$ & 2.692 & 11.970 & $* * *$ & 3.369 & -3.209 & & 4.253 & -1.427 & & 3.908 \\
\hline Sweden & -11.564 & $* * *$ & 3.365 & 14.158 & $* * *$ & 4.461 & -7.082 & $* * *$ & 2.650 & 8.250 & & 6.075 \\
\hline United Kingdom & -21.128 & $* * *$ & 3.218 & 12.342 & $* * *$ & 4.026 & 3.516 & & 3.551 & 6.007 & & 3.972 \\
\hline
\end{tabular}

***: $p<0.01 ;{ }^{* *}: p<0.05 ; *: p<0.1$

Figure 3 Summarizes the relations between skill mismatches and labour market outcomes across all countries, in other words the international average coefficients. For ease of comparison between outcomes we present the standardized regression coefficients (betas), rather than unstandardized (B) coefficients such as are presented in Tables 1 to 3.

Figure 3: International average relation between skill mismatches and labour market outcomes 


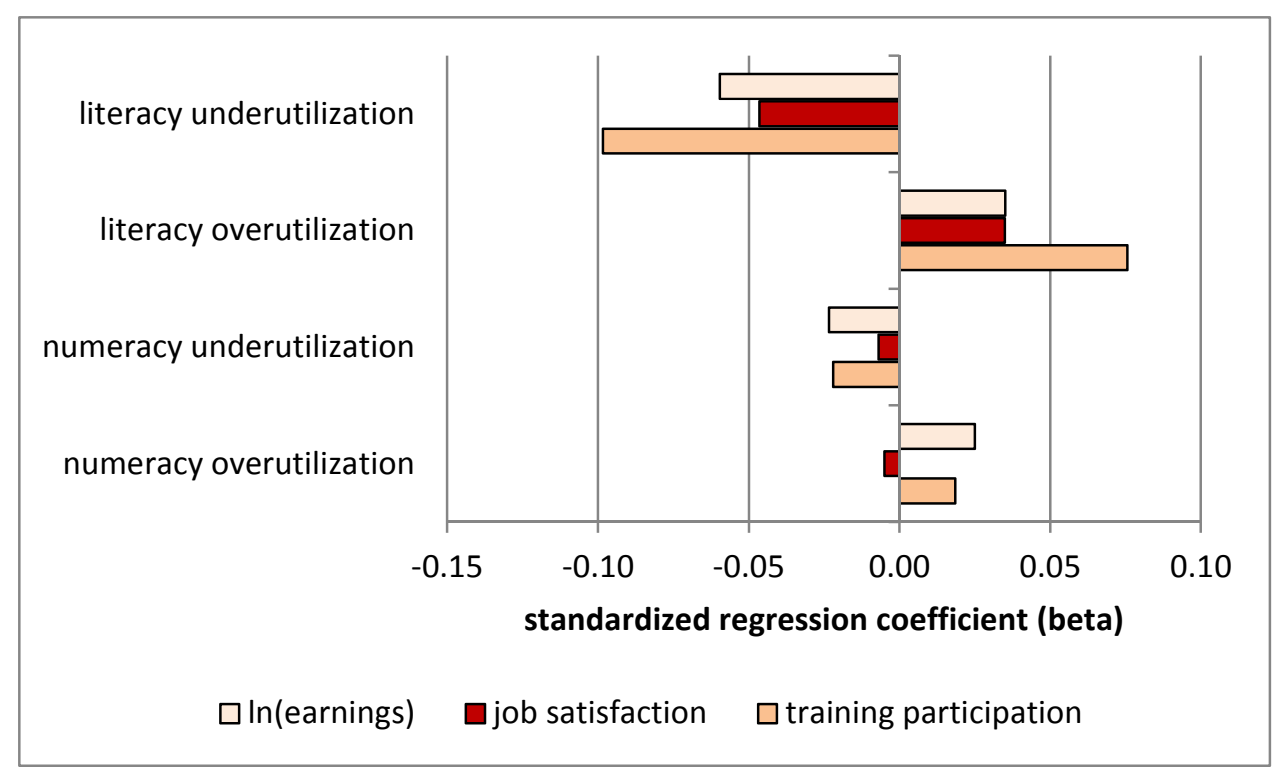

With the exception of the small (and non-significant) negative relationship between numeracy underutilization and job satisfaction, the relationships all point in the same direction, namely a negative relationship with underutilization, and a somewhat smaller positive relationship with overutilization. In general literacy mismatches appear to matter more for labour market outcomes than numeracy mismatches. In the case of earnings, this is surprising, since it appears that numeracy skill level is more important for labour market outcomes than literacy level. It would require a shift of roughly three standard deviations in the literacy skill level scale to produce a shift in earnings of $10.5 \%$, which is the average earning decrease associated with literacy underutilization. A comparable shift in numeracy skill level is related to an $18.5 \%$ shift in earnings, whereas numeracy underutilization leads to just a $3.7 \%$ drop in earnings. This may suggest that having numeracy skills is always conducive to productivity, regardless of how much those skills are used, whereas literacy is very dependent on use to be productive. Alternatively, it may be that, in terms of its effects in the labour market, numeracy skills to some extent proxy a broader range of abilities, including general intelligence, that is productive across a broader range of skill usage domains than simply the use of numbers and calculations. In that case our numeracy mismatch measure may not capture the extent to which this broader range of skills are used.

There is little discernible pattern in the results across countries. The results are consistent with the expectations, and as such provide a strong validation of our mismatch measure. Underutilization is generally strongly negative in its relation with outcomes, and appears to reduce the propensity of workers to engage in training. Overutilization is generally positive in its relations with outcomes, and is related to a higher degree of training participation. Although the coefficients for overutilization are generally smaller than those for underutilization, the positive relationships support the notion of 
"supermatching": a fuller use of skills than is achieved by well-matched workers, resulting in higher wages and greater job satisfaction.

\section{What can we learn from differences between sub-populations?}

\subsection{Introduction}

In this section we present differences in the incidence of mismatches between relevant subpopulations. We start with a broad comparison of countries, before zooming in on differences that may occur within countries. We look for differences according to educational mismatch, broad economic sector, firm size and, specifically for workers whose highest education is at secondary level, whether that education was general of vocationally specific. These differences are interesting in their own right, since they point to sub-populations that could be of interest to policy makers in the areas of education and the labour market. They are also interesting because they may shed light on what is driving mismatches.

Although we make no claims towards demonstrating causality, we will take into consideration some frequently heard theoretical ideas about possible causal factors for mismatches when looking at the results. Broadly speaking, problems can arise on both the supply and the demand sides of the labour market, as well as in the functioning of mechanisms and institutions that aim to bring supply and demand together.

The most simple account of why skill mismatches occur is simply a matter of aggregate supply and demand. Education systems may be producing too many or too few skills compared to the requirements of the economy, and conversely employers may be using the available skills to a greater or lesser extent. This type of mismatch can probably not be resolved in the short term, but only in the longer term, for example through education reform or shifts in the balance of high-skill versus low-skill production processes. With respect to shortages, such "imbalances" are by no means obviously a bad thing. A high aggregate level of skill use relative to skill level in a country, or in certain types of firms or organizations within countries, may be indicative of production processes that are heavily geared towards extracting as much value as possible from the available skill supply. This propensity may be quite general, and reflect a general propensity towards value extraction, or skill-specific, in which case it reflects more a particular mode of production. 
Given the aggregate supply and demand, employers and/or employees can be more or less successful in ensuring that the right person ends up in the right job. This can be achieved in a variety of ways, such as effective search and/or selection strategies, flexible adjustments within and between firms, investments in training, and so on. These processes may be influenced by the institutional arrangements in countries. On the supply side, education systems in many countries have been designed to incorporate strong linkages with employers, and so to smoothen the transition from education and work and ensure that it is easy for both employer and employee to find their way to obtaining a good match. On the demand side, differences in labour legislation in different countries may affect the ability of employers and/or employees to adjust flexibly to situations in which mismatches occur, in order to achieve a more optimal allocation of people over jobs.

In the next section we show the pattern of mismatches across countries, revealing countries that are using the available skills a great deal as well as countries that appear to be making much less use available human capital. We reflect on whether these country differences line up in any obvious way with any known institutional features of those countries.

We then look at differences in mismatches within countries. We first of all tackle the important question of the extent to which educational mismatches are reflected in skill mismatches. We then compare the private and public sectors to establish whether there is any systematic evidence for misallocation and or sub-optimal utilization of skills across these two broad segments of the labour market. We subsequently look at the relation between mismatches and firm size. Finally, we compare the extent of mismatch of people a vocational form of secondary qualifications with people with general secondary qualifications, which may provide a more direct indication of the effect of institutional arrangements on the individual level.

\subsection{What can we learn from country differences?}

Country differences in average skill level and skill use

Before we show country differences in the mismatches themselves, we start in Figure 4 by showing how the component measures, skill levels and skill use, are distributed across countries. This is useful, since it helps give us a picture of countries that are susceptible to underutilization or overutilization, based on their mean skill level and skill use. 
Figure 4: Mean skill level and skill use per country

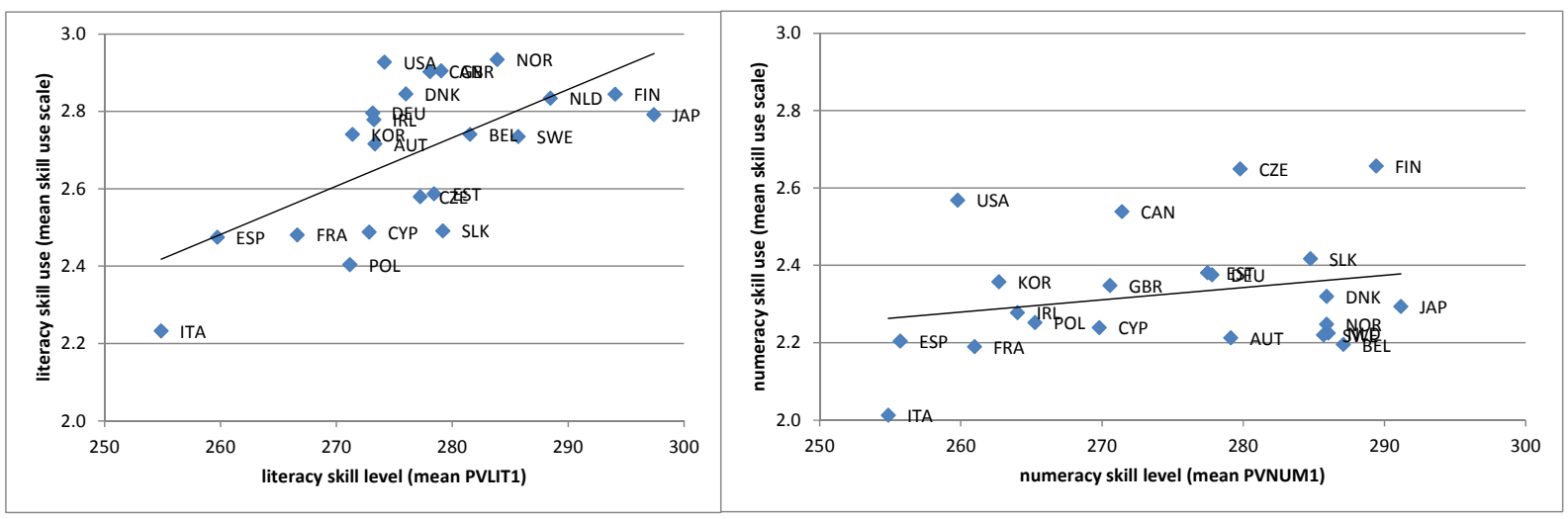

The first thing we notice from this is that, whereas the distribution of skill levels across countries is broadly similar across the two skill domains, the distribution of skill use is very different for literacy and numeracy. The most noticeable difference is that the scale values of numeracy use are much lower than those for numeracy. Of all countries only the Czech Republic shows a slightly higher scale value for numeracy than for literacy. This may indicate that the use of literacy skills is more extensive in the working environment of developed countries than that of numeracy skills. This seems intuitively plausible, but it is advisable to exercise caution in interpreting these differences. In fact it is questionable to what extent the scales are comparable. Recall that the scales are directly derived from the reported frequencies of respondents on a range of activities. The typically reported frequencies vary strongly by activity, both within and between the skill domains. There is no a priori reason to expect these frequencies to be comparable on average across the two domains.

Arguably more meaningful than the difference in the mean extent of skill use is the fact that, other than is the case with skill levels, the ranking of countries in terms of skill use is very different across the two skill domains. For example, the Czech Republic show the second highest degree of use of numeracy skills (after Finland) but is ranked 16th out of these 22 countries in terms of use of literacy skills. Conversely, Norway shows the highest average use of literacy skills, but is well below the international average in terms of use of numeracy skills. As a consequence of this, there is very little relation between numeracy skill level and use at the level of countries. The main consequence of this is that, whereas countries with a give average extent of literacy skill use tend to lie within a relatively narrow ban in terms of average literacy skill level, for numeracy the skill levels cover pretty much the entire bandwidth of countries at each average level of skill use. 


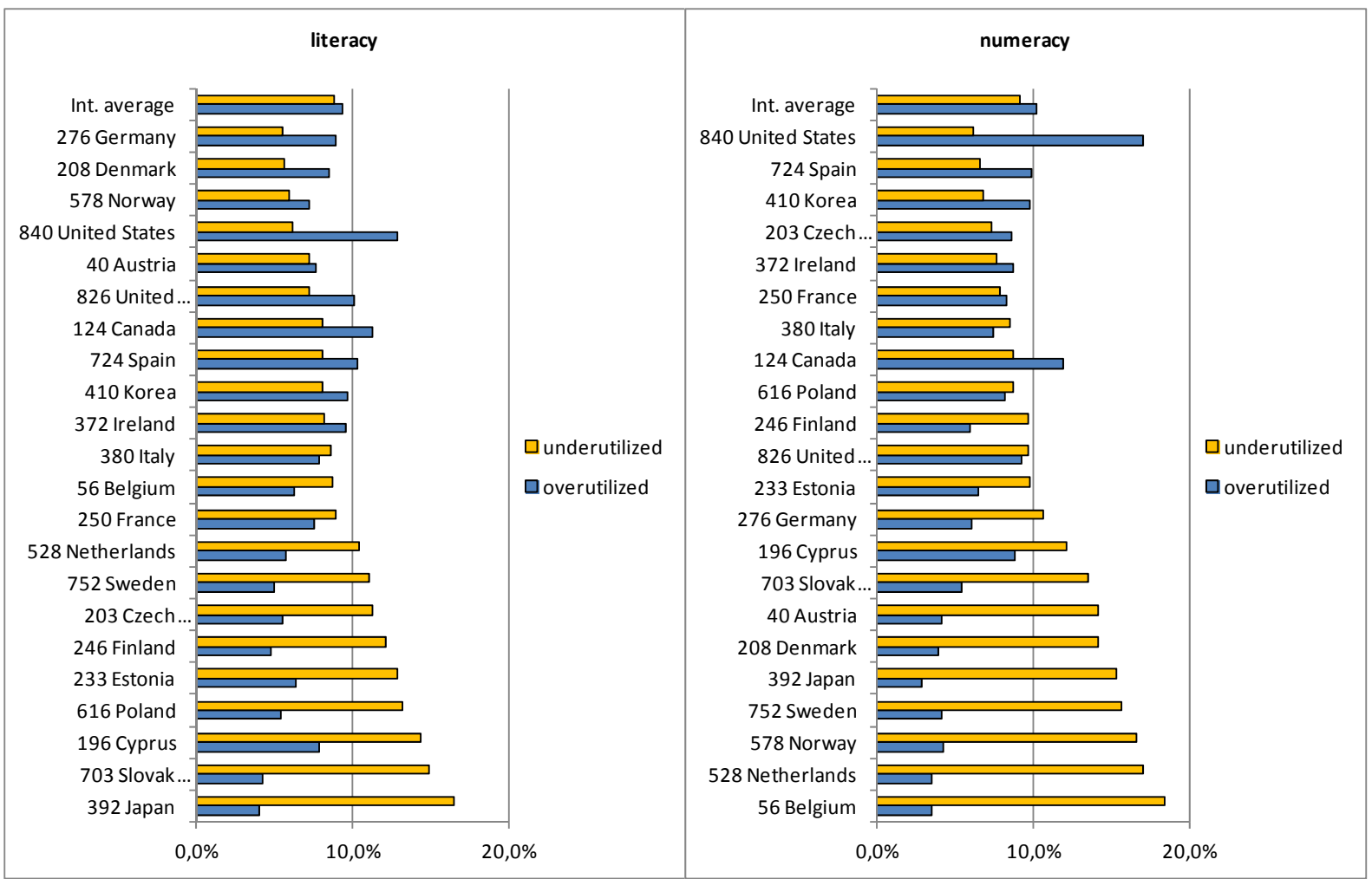

The pattern of mismatches is close to what might be expected based on Figure 4. Taking account both overutilization and underutilization, the United States, Canada and Germany are the most overutilized in literacy terms, and Japan, Slovakia, Finland and Poland the most underutilized. In the case of numeracy United States and Canada are again strongly overutilized, this time joined by Korea, Spain and the Czech Republic. Japan is joined by Belgium, the Netherlands, Sweden and Norway as the most underutilized countries in terms of numeracy.

It is noticeable that the ranking according to underutilization is not the exact opposite of that according to overutilization. This is due to the fact that the total proportion of mismatches is greater in some countries than in others. This proportion ranges from $13 \%$ in Norway to $22 \%$ in Cyprus for literacy, and from $16 \%$ in Finland to $23 \%$ in the US for numeracy. This suggests that the pattern of mismatches across countries is not entirely determined by the distribution of skills relative to skill use, as Figure 1 would suggest, but also partly by the allocation of workers with given skill levels across jobs with given skill requirements. A high overall proportion of skill mismatches may indicate that this allocation is less than optimal. Despite such misallocations, the ordering of countries according to the combined measure quite strongly follows what one would expect based on the distributions in figure 1, which form the basis for the combined measure. This suggests that country 
differences are mainly driven by the demand for skills in relation to their supply. The position of the US is particularly striking: both in terms of literacy and especially numeracy, it is by far the most strongly overutilized country. Canada and Spain are also countries that seem to be geared towards a relatively high degree of use of the available skills in general. Germany seems strongly geared towards a strong use of its literacy skills, but less so for its numeracy skills.

At the other end of the spectrum, Japan seems to be the country which shows a lowest propensity to use the available skills in general. Other countries show a more skill-specific low propensity, such as the Slovak Republic and Cyprus in the case of literacy and the Netherlands and Belgium in the case of numeracy.

These results are intriguing, but on their own don't appear to offer us any clear "smoking gun" that might tell use the root cause of the differences. Several of the countries showing a predominance of underutilization, such as the United States and Canada, are generally perceived as relatively "free market" countries, as indicated by, for example, the extent of employment protection legislation. Conversely, several countries that are heavily underutilized, such as the Netherlands, Belgium and the Scandinavian countries, can be described as having relatively regulated economies. There are however partial exceptions that don't fit this pattern, such as Japan, which is heavily underutilized despite not having strong employment legislation, ${ }^{12}$ and Spain, which is moderately regulated but quite heavily overutilized. The picture is further clouded by the fact that the countries that do fit the low-regulation-high skill use and vice versa pattern can be equally well accounted for by positing a relation with a different system characteristic, such as the prevalence of vocational education. Realistically, at this point there doesn't seem to be a clear cut case for any of these explanations, especially when one considers the fact that the pattern is quite different for literacy and numeracy. For the moment we suffice with the observation that there are countries that make strong use of one or both skills, and countries that, for whatever reason, appear to leave a large pool of skills underutilized.

\subsection{What can we learn from differences within countries?}

In this section we estimate the relationships between a number of characteristics that vary within countries and the degree to which people are underutilized or overutilized in terms of literacy and numeracy. We simultaneously estimate the relationships with educational mismatch (as opposed to having a job that matches one's own education), working in the public sector (as opposed to the private sector), firm size, age, occupation level, and for workers whose highest education is at

12. Although it may be that such legislation is rendered unnecessary by Japanese traditions of long term labor relationships and seniority promotion. 
secondary level, whether they completed vocational education (as opposed to general education). In all analyses we control for highest level of education, gender and ethnicity, in addition to the characteristics presented. We have made separate analyses per country, the results of which are included in an appendix. We show below only the average results across countries.

\section{Relationship between educational and skill mismatches}

The most obvious cause of skill mismatches at an individual level is educational mismatch, that is, being employed in a job requiring a higher or lower level of education than one's own. Figure 6 shows this relationship for literacy skills. The graph shows the estimated deviation of workers who underutilize or overutilize their skills compared to a respondent who is well-matched in terms of the skill involved. Table A1 in the appendix shows the full results per country.

Figure 6: Relation between educational mismatch and skill mismatches, international average

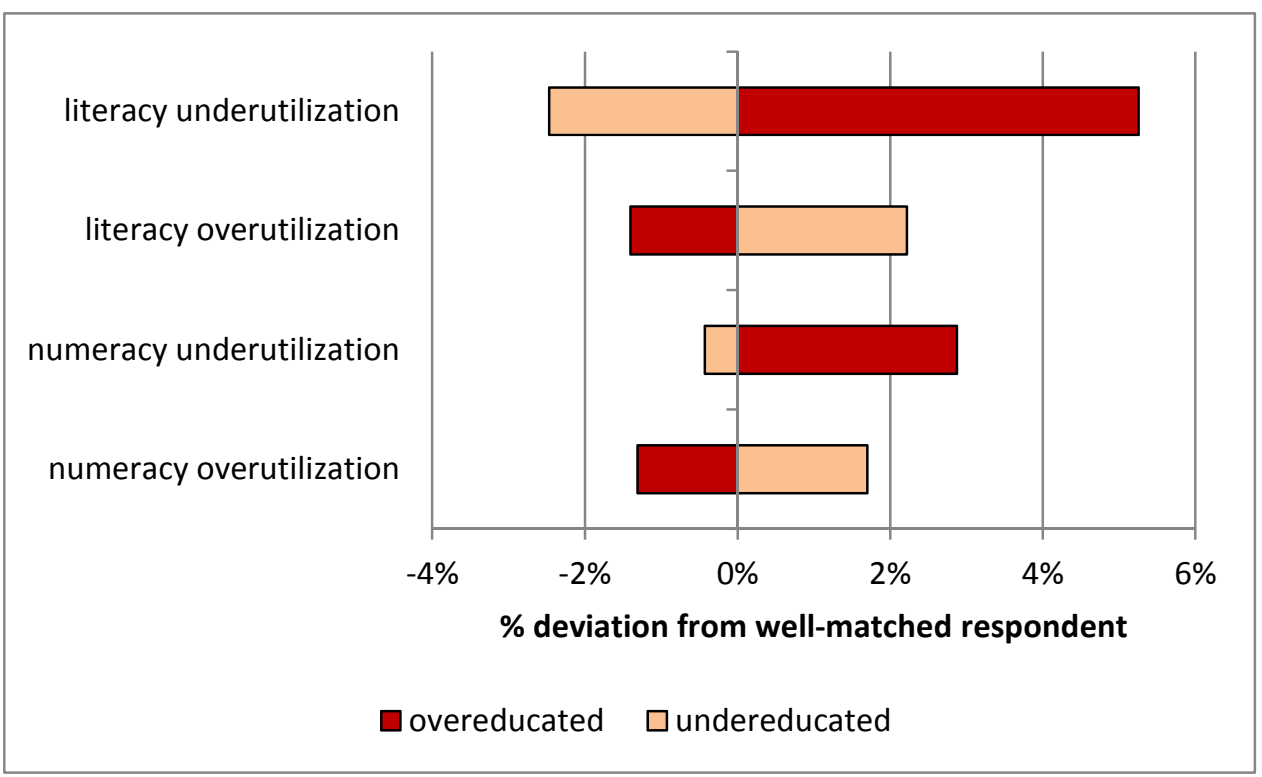

Figure 6 shows that the match between one's own education and one's job has a stronger relationship with the percentage of workers who are underutilized in terms of literacy than on the percentage of overutilized workers. The clearest relationships are those between overeducation and overutilization. However, even these are not huge by any means. Recalling that Figure 5 revealed that underutilization and overutilization accounted each for around $9 \%$ of workers across all countries, only the change in underutilization associated with overeducation - just over $5 \%$ across all countries, an increase of some $60 \%$ - can be regarded as reasonably large. The overall changes in overutilization associated with both overeducation and undereducation, and of underutilization associated with undereducation, are quite modest, and the results per country shown in the Table A1 in the appendix reveal that these are not always significant or even in the expected direction. The 
relationships with overeducation are even smaller in the case of numeracy, both in an absolute sense and as a proportion of the percentages in the population as a whole.

At first glance, the smallness of the relations between educational mismatches and skill mismatches seems strange. However, closer inspection of the data reveals why this is the case. Across both skill domains, overeducation is associated with both lower skill levels and lower skill use, while undereducation is associated with higher skill levels and use. The relationships are quite strong in most countries. In the mismatch literature, the link between educational mismatch and skill use is usually assumed to be present, while the link with skill level is frequently ignored. To be clear, the link is indeed somewhat stronger in the case of skill use than in the case of skill level, which is why we observe a residual relationship between educational mismatches and skill mismatches. But the strong sorting in terms of skill levels between overeducated, well-matched, and undereducated workers has the effect that educational mismatch is a less serious problem than it is frequently perceived as being. The bad news is that a significant proportion of workers who are well-matched in their jobs in terms of their education are in fact badly matched in terms of skills.

\section{Relationship between economic sector and skill mismatches}

We now look at the prevalence of skill mismatches separately for the private and public sectors. This comparison of interest because it is often assumed that public sector labour markets work rather differently to those in the private sector. In the latter sector, the pursuit of profits in competition with other firms operating on the same market gives employers a clear yardstick on which to gauge their performance. Public sector organizations are often said to lack such a yardstick, and their performance is assessed against other, externally imposed goals and targets.

Such a distinction between the two sectors is arguably too simplistic and outdated. In terms of their day to day running, the distinction between private and public sector organizations is often not that clear. Public sector organizations, and especially units within those organizations, are increasingly expected to operate in an entrepreneurial manner and to compete for resources and sometimes for their very existence with other organizations or units. Conversely, the operations of many private sector firms, especially larger ones, are so complex that they have little choice but to apply administrative procedures similar to those commonly associated with the public sector. Only in a relatively few cases is it likely to be possible to objectively assess the contribution of individual employees to the overall performance of the firm or organization.

With these reflections in mind, Figure 7 shows difference in the proportions of underutilized and overutilized workers in the public sector compared to the private sector, once again corrected for 
highest level of education, level of occupation, age, gender and ethnicity, in addition to the other characteristics presented. Table A2 in the appendix shows the full results per country.

Figure 7: Relation between working in the public/non-profit sector (versus private sector) and skill mismatches

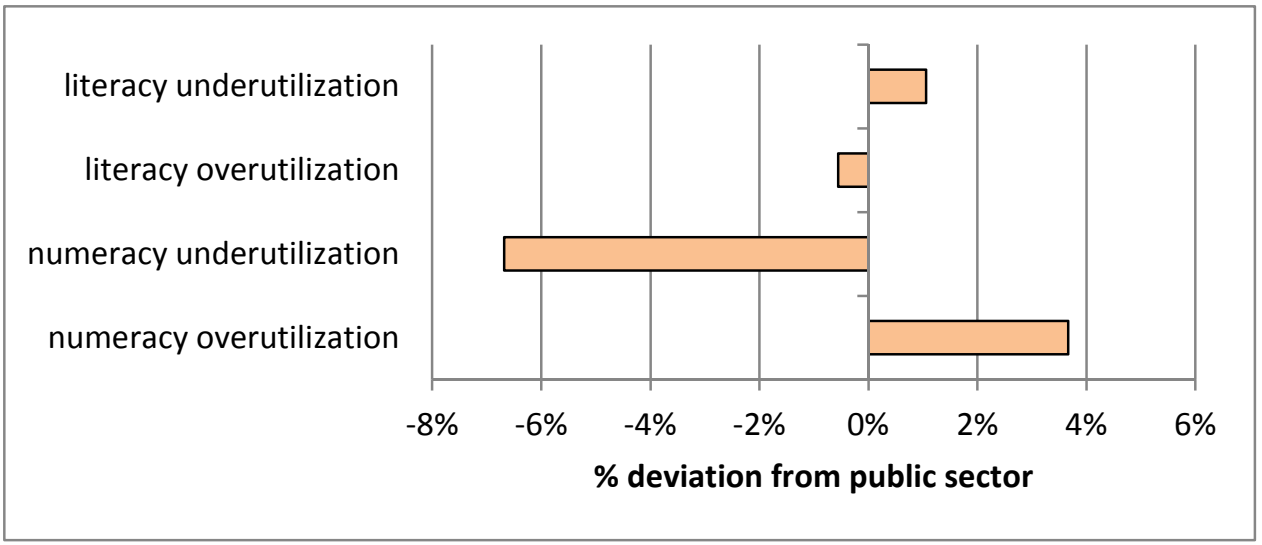

There is very little difference between the public and private sectors in terms of literacy mismatches. The difference is far greater in terms of numeracy skills, in the "expected" direction. There is around $7 \%$ less underutilization and $4 \%$ more overutilization across all countries in the private sector compared to the public sector. As Table A2 in the appendix shows, this difference is observed in almost all countries. It is conceivable that this is driven by the prevalence of firms strongly geared towards the use of numbers and calculations in the private sector, but further analysis shows that it turns out to be quite general across widely different kinds of private sector firms. It seems more plausible that these results reflect a different attitude towards value extraction in the private sector compared to the public sector, with the former far more oriented towards using numerical skills.

\section{Relation between skill mismatch and firm size}

As mentioned above, even in the private sector, large firms face such complexity in their operations that they may have little choice but to apply quite bureaucratic administrative procedures, which may make it more difficult to achieve a good match between actual and required skills on an individual level. Smaller firms by contrast are in a position in which they can quickly observe when a worker is not well-matched to the job. As a consequence, it may be that large firms are more susceptible to skill mismatches than are smaller firms. Figure 8 shows this relation for literacy and numeracy mismatches. Table A3 in the appendix shows the full results per country. 


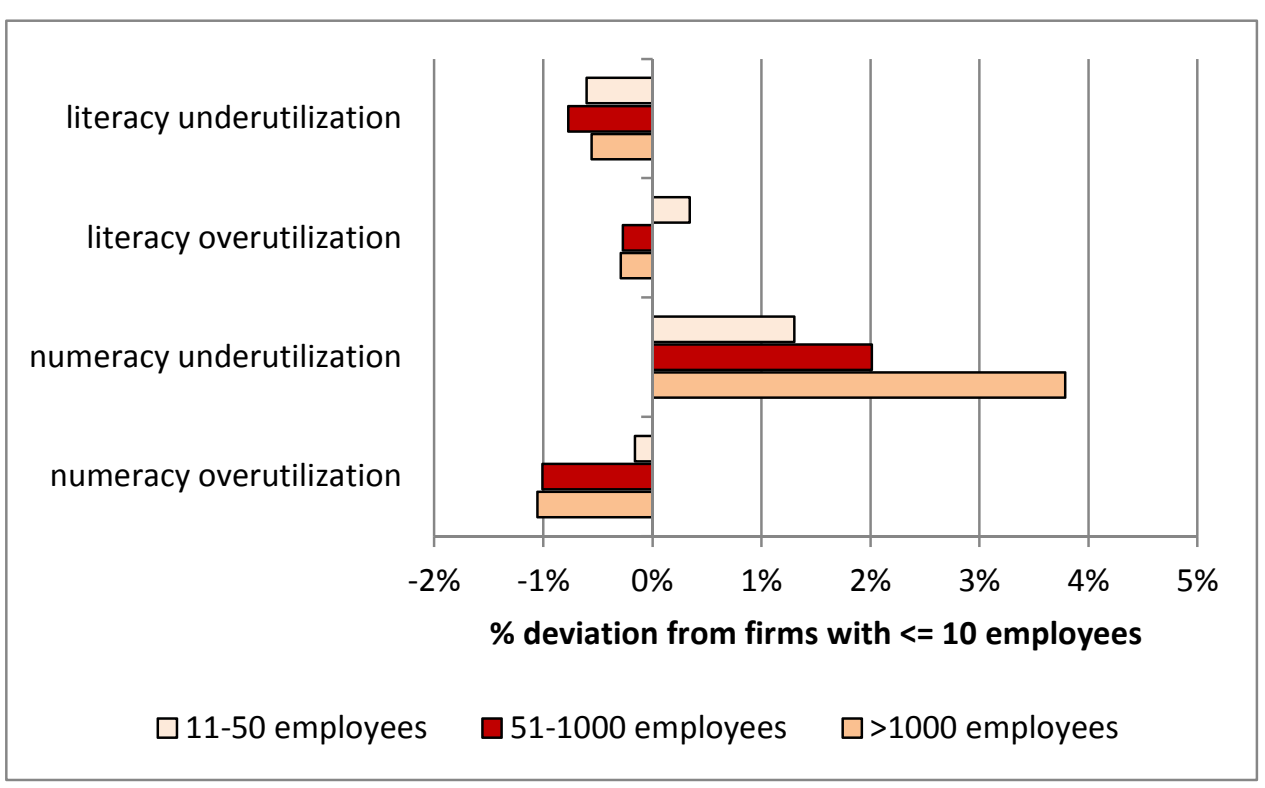

Intriguingly, Figure 8 shows a similar pattern to what we saw for public versus private sector. There is little or no relation in terms of literacy, but a much stronger pattern of more underutilization and somewhat less overutilization in terms of numeracy, in larger firms compared to small firms. This seems to suggest that smaller firms better able to use the available numeracy skills than larger firms. Perhaps their smaller size allows them to identify and root out wastage of these valuable skills more quickly than larger and more complex firms are able to. Alternatively, it may be a matter of selection processes, with the scale advantages of larger firms allowing them to absorb and survive a certain amount of wastage, whereas smaller firms that do not use their resources optimally are forced out of business.

\section{Relation between age and skill mismatches}

The OECD (2013a) finds that in many countries, young workers are significantly more likely to be overskilled (underutilize their skills) than older workers. The interpret this in terms of search and information costs, arguing that it takes time for people to find their niche in the labour market, so that one might expect mismatches to become less prevalent over time. Figure 9 examines this notion by plotting the estimated relation between age and mismatches. We included both a linear and a quadratic predictor. Table A4 in the appendix shows the full results per country. 


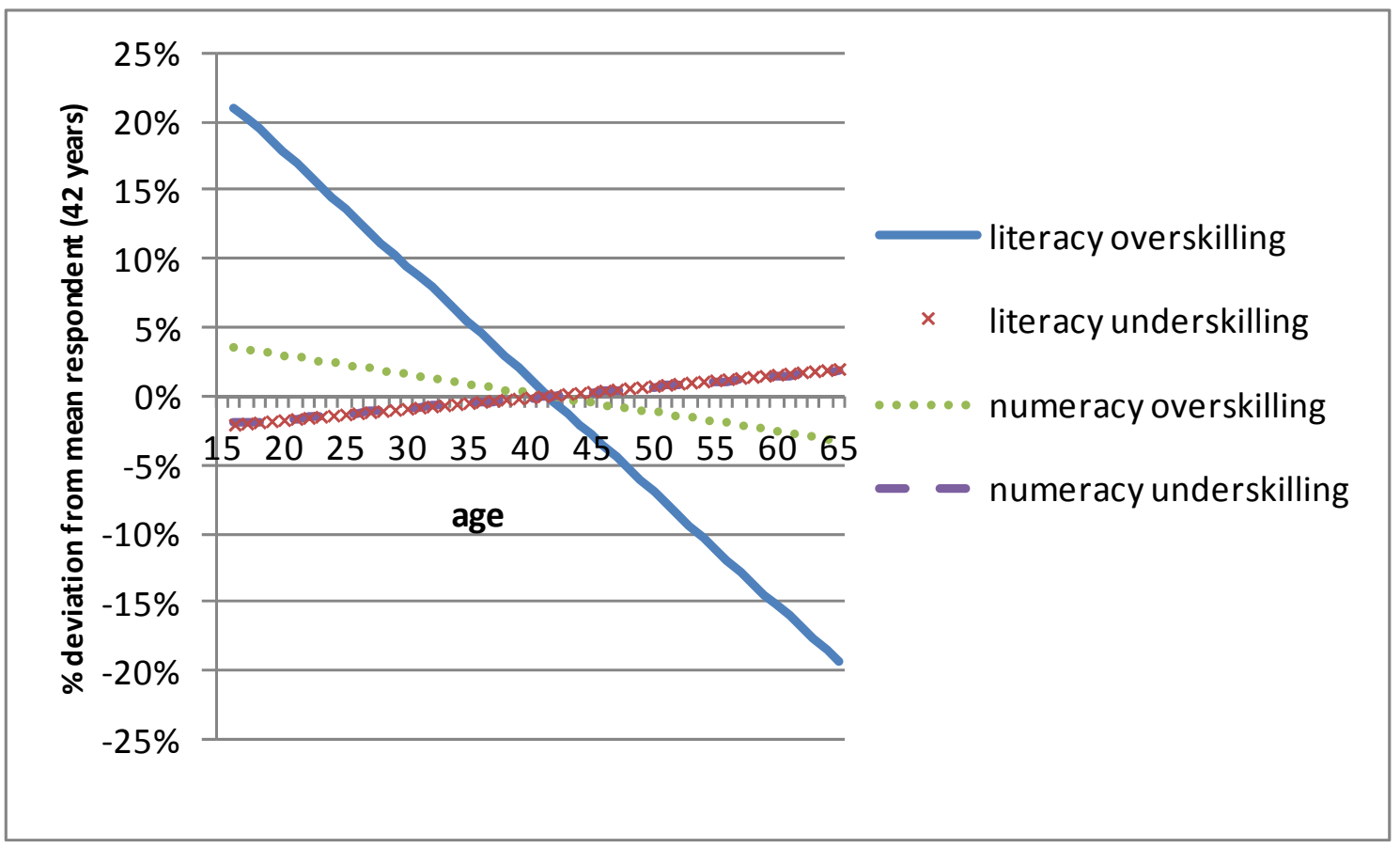

The expected relation with age only appears to exist in the case of literacy underutilization. The relation is however very strong, and nearly linear. Consistent with the OECD's findings, literacy underutilization appears to be very much a young person's problem. The same does not however apply to numeracy underutilization, or for either type of overutilization, none of which are significantly related to age. Table A4 in the appendix reveals that, in countries where relationships are significant, these almost always point towards decreasing underutilization and increasing overutilization with age. In our view, this pattern is more consistent with an increase in responsibility over the life course, with workers taking on more demanding tasks as they grow older, rather than to a better match per se, as suggested by the OECD. We should also point out that the relation with age could equally point to a pure age or life-cycle effect or a cohort effect. The data do not allow us to distinguish these possibilities.

\section{Relation between occupation level and skill mismatches.}

Like educational matches, the level of the occupation in which people work may be expected to have a rather direct relation with skill mismatches. Holding other characteristics constant, we can expect workers in higher level occupations to experience less underutilization and more overutilization than workers in lower level occupations. Figure 10 shows this relation. Table A5 in the appendix shows the full results per country. 
Figure 10: Relation between occupational level and skill mismatches

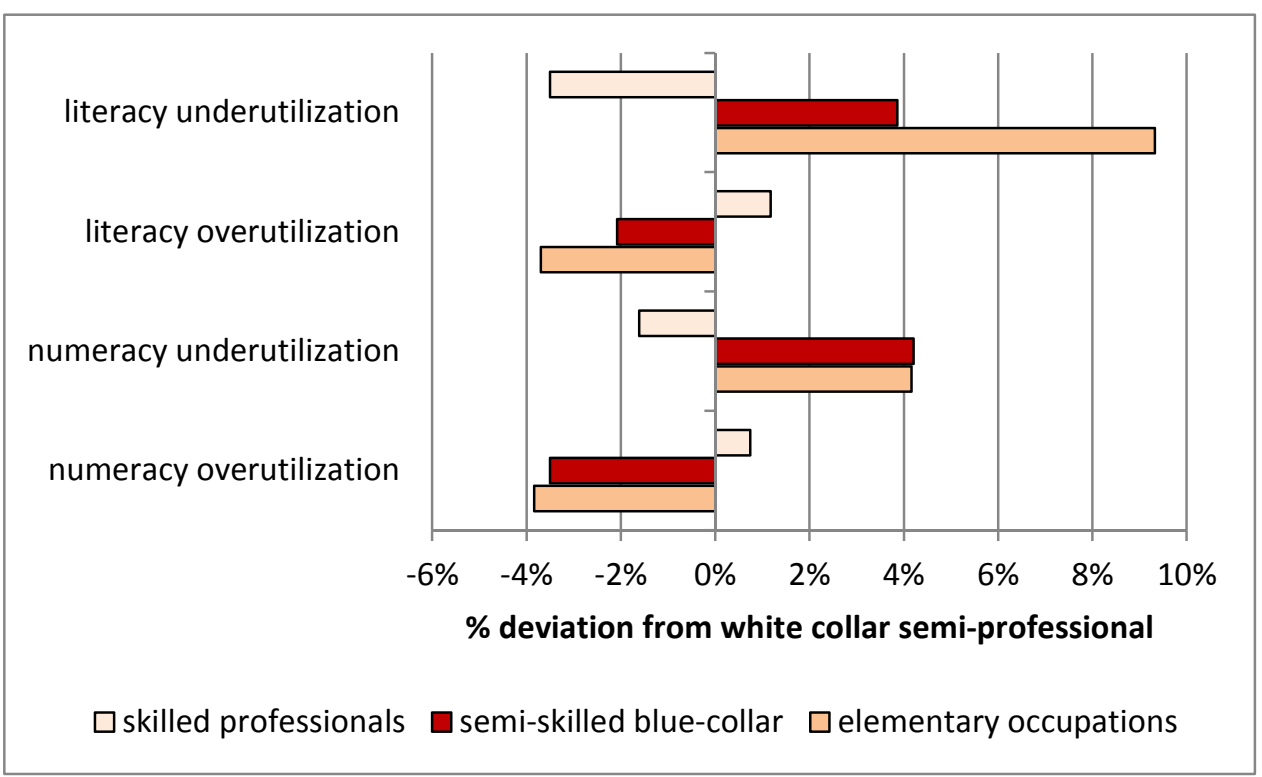

As one might expect, there is a strong relationship between occupational level and skill mismatches. Those employed as skilled professionals are less likely to be underutilized and somewhat more likely to be overutilized than those employed as white-collar semi-professionals. The opposite is true of semi-skilled blue collar workers and especially those employed in elementary occupations.

\section{VET versus non-VET}

The analyses presented in Figure 11 are restricted to respondents whose highest completed education is at secondary level. Again, the results are corrected for relevant personal characteristics, qualifications and work aspects. We show the change in the proportion of mismatched workers of people whose highest completed education is a secondary vocational (VET) qualification, compared to those whose highest completed education is non-vocational secondary education. Table A6 in the appendix shows the full results per country. 


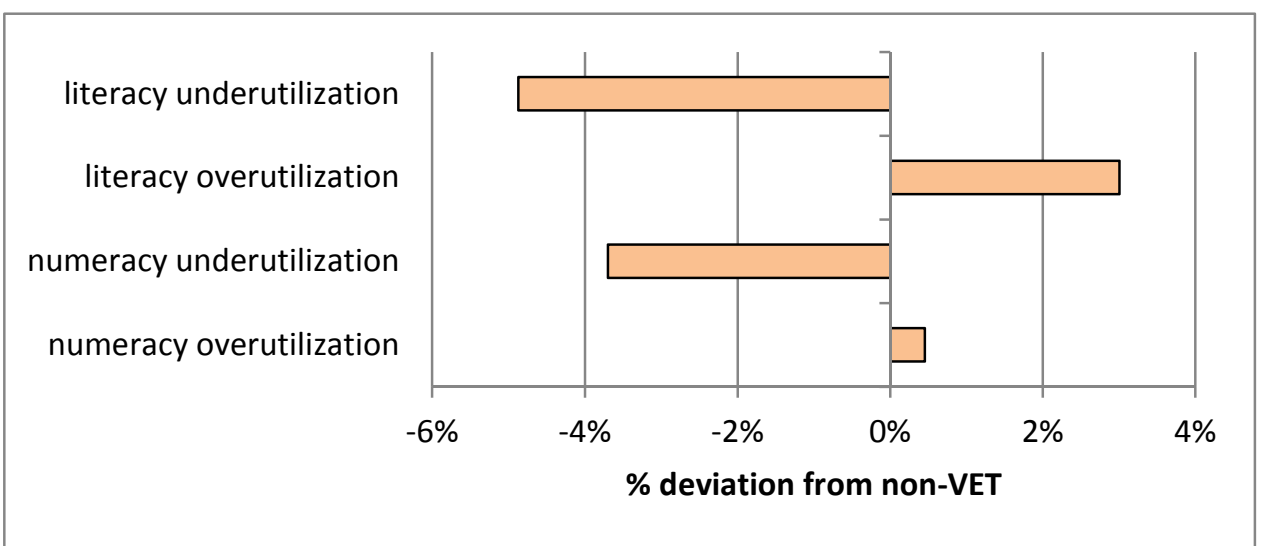

As Table A6 in the appendix shows, the coefficients are not significant in all countries, but with one minor exception, they all point in the direction of graduates of VET programmes being less underutilized and more overutilized that graduates of non-VET programmes. Interestingly the coefficients appear to be largest in countries with strongly developed VET systems. The results suggest that, although countries with strongly developed VET systems often appear to score quite poorly in terms of skill use, within countries participation in VET is associated with a better use of skills in the labour market. This result is all the more striking considering the fact that these skills are general basic skills rather than occupation specific skills. ${ }^{13}$

\section{Conclusions}

In this paper we have developed and tested a new measure of skill mismatches, one that is based on skill levels and skill use of individual workers. Our measure represents the level of skill use relative to the level of skill a worker possesses. The measure appears to work, and produces interesting and largely plausible results. It is superior in almost every respect to alternative measures based on skill distributions within broad occupational categories, such as is used by the OECD (2013a).

The relations between mismatches and outcomes are consistent with both theoretical expectations and findings from prior research into educational mismatches and subjective skill mismatches. We find strong positive relations between overutilization and wages, job satisfaction and training participation, and somewhat stronger negative relations between underutilization and outcomes. These results provide support for the expectation that, after controlling for skills, education and

13. It should be remarked that especially in strong VET countries, it is likely that the sorting into VET versus non-VET programmes is likely to be based on skills as well as some unobserved characteristics. Although this appears to be true in the case of skills, it is not clear how this would lead to the effects seen in Figure 11. 
other relevant characteristics, workers suffer a penalty when they make little use of their skills. Conversely, when workers use their skills more than other workers with a similar level of skill, they experience higher earnings and job satisfaction, and engage in more training. As mentioned, this is consistent with findings from prior research, and suggests that "supermatching" interpretation of overutilization, whereby workers use skills that "well-matched" workers have in reserve, rather than encountering any serious skill shortages. This is supported by the finding that around three quarters of workers who overutilize their skills report that they could handle more demanding work than they are currently performing.

In general, literacy mismatches appear to matter more for labour market outcomes than numeracy mismatches. In the case of earnings, this is surprising, since it appears that numeracy skill level is more important for labour market outcomes than literacy level. This may suggest that having numeracy skills is always conducive to productivity, regardless of how much those skills are used, whereas literacy is very dependent on use to be productive. Alternatively, it may be that, in terms of its effects in the labour market, numeracy skills to some extent proxy a broader range of abilities, including general intelligence, that is productive across a broader range of skill usage domains than simply the use of numbers and calculations. In that case our measure of numeracy mismatch might not be as effective as our literacy measure.

Country differences in skill mismatches seem to be driven mostly by differences in value extraction propensity, i.e. the propensity towards high skill use for a given skill level. This is in many cases rather skill-specific, but some mainly Anglo-saxon countries, especially the USA, appear to be strongly geared towards value extraction across both skill domains. This pattern could be explained by differences in institutional arrangements in countries, such as those affecting employment protection or the prevalence of vocational systems, but the large number of exceptions to this cast doubt on these interpretations. Interestingly, we find that at an individual level, participation in vocational as opposed to general secondary education appears to be related to higher skill use relative to the level of available skills, whereas at a system level it seems to be mainly countries lacking a strongly developed VET system that show the highest skill use.

The relationships with educational mismatch are more or less in the expected directions, but are surprisingly weak. The reason for this is the finding that people who are mismatched in terms of their education not only face different skill requirements than people who are well matched, but possess correspondingly different skills. The flip side of this is the fact that a large proportion of workers whose job fits well with their education are clearly mismatched in terms of skills. We observe similar 
relationships with occupation level, with workers in high level jobs using their skills more than comparable workers in lower-level jobs.

The relation between working in the public versus private sector and mismatches are consistent with the notion of more effective value extraction in the market-oriented private sector. This result is concentrated in the numeracy domain, which as pointed out above is the domain in which skills themselves are most highly rewarded. Workers in the private sector are less likely to underutilize their numeracy skills and more likely to overutilize them, than comparable workers in the public sector. A similar picture applies to large versus small firms, suggesting that smaller firms make better use of the available skills than do their larger counterparts.

Consistent with findings by OECD, literacy underutilization appears to be very much a young person's problem. The same does not however apply to numeracy underutilization, or for either type of overutilization, none of which are significantly related to age across all countries, but positively related to age in several countries. In our view, this pattern is more consistent with an increase in responsibility over the life course, with workers taking on more demanding tasks as they grow older, rather than with an improved match, which was the OECD's interpretation of their findings. 


\section{References}

Allen, J. and A. de Grip (2012). Skill Obsolescence, Lifelong Learning and Labor Market Participation, Applied Economics, vol. 44 (25), 3237-3245.

Allen, J. and R. van der Velden (2001) "Educational Mismatches versus Skill Mismatches: Effects on Wages, Job Satisfaction, and On-the-Job Search", Oxford Economic Papers, Vol. 53, No. 3, pp. 434-452.

Duncan, G., \& Hoffman, S. D. (1981). The incidence and wage effects of overeducation. Economics of Education Review, 1(1): pp. 75-86

Green, F. and S. McIntosh (2007), "Is There a Genuine Under-Utilization of Skills Amongst the OverQualified?", Applied Economics, Vol. 39, pp. 427-439.

Green, F., S. Mclntosh and A. Vignoles (1999), "Overeducation and Skills -Clarifying the Concepts", Centre for Economic Performance, Discussion Paper 435.

Groot, W. \& H. Maassen van den Brink (2000), Overeducation in the labour market, a Meta-analysis'. Economics of Education Review, 19:p.149-158.

Hartog, J. (2000). Overeducation and Earnings: where are we, where should we go? Economics of Ecucation Review, 19: pp.131-147.

Leuven E. and H. Oosterbeek, (2011) Overeducation and mismatch in the labor market. IZA Discussion Paper No. 5523. Available at SSRN: http://ssm.com/abstract=1771245.

OECD (2013a). Skills Outlook: first results from the OECD Survey of Adult Skills (Volume 1), Paris: OECD Publishing.

OECD (2013b). PIAAC Data. Paris: OECD.

OECD (2013c). Technical Report of the OECD Survey of Adult Skills (PIAAC). Paris: OECD Publishing.

Quintini, G. (2011) Over-qualified or Under-skilled: A Review of Existing literature, OECD Social, Employment and Migration Working Paper No. 121.

Sicherman, N. (1991). Overeducation in the labour market. Journal of Labour Economics, 9 (2), 101122. 
Sloane, P. (2003), "Much Ado About Nothing? What Does the Overeducation Literature Really Tell Us?”, in Buchel, in F. Büchel, A. de Grip and A. Mertens (eds), Over-education in Europe: Current issues in theory and policy, Edward Elgar, Cheltenham.

Verdugo, R. and N. Verdugo (1989), "The Impact of Surplus Schooling on Earnings: Some Additional Findings", Journal of Human Resources, Vol. 24, pp. 629-643. 


\section{Appendix}

Table A1: Effect of educational match on skill mismatches, per country

\begin{tabular}{|c|c|c|c|c|c|c|c|c|c|c|c|c|}
\hline \multirow{3}{*}{$\begin{array}{l}\text { Literacy: } \\
\text { country }\end{array}$} & \multicolumn{6}{|c|}{ underutilization } & \multicolumn{6}{|c|}{ overutilization } \\
\hline & \multicolumn{3}{|c|}{ overeducated } & \multicolumn{3}{|c|}{ undereducated } & \multicolumn{3}{|c|}{ overeducated } & \multicolumn{3}{|c|}{ undereducated } \\
\hline & $\mathrm{B}$ & & S.E. & $\mathrm{B}$ & & S.E. & $\mathrm{B}$ & & S.E. & $\mathrm{B}$ & & S.E. \\
\hline Austria & 0.040 & $* * *$ & 0.015 & -0.027 & $* *$ & 0.011 & -0.033 & $* *$ & 0.013 & -0.008 & & 0.016 \\
\hline Belgium & 0.061 & $* * *$ & 0.014 & -0.008 & & 0.012 & -0.016 & & 0.011 & 0.005 & & 0.014 \\
\hline Canada & 0.040 & $* * *$ & 0.009 & -0.005 & & 0.009 & -0.002 & & 0.010 & 0.023 & & 0.014 \\
\hline Cyprus & 0.094 & $* * *$ & 0.025 & -0.108 & $* * *$ & 0.018 & -0.006 & & 0.016 & 0.061 & $* * *$ & 0.017 \\
\hline Czech Republic & 0.057 & $* *$ & 0.027 & -0.048 & $*$ & 0.028 & 0.003 & & 0.012 & 0.029 & & 0.029 \\
\hline Denmark & 0.053 & $* * *$ & 0.013 & -0.007 & & 0.011 & -0.007 & & 0.011 & -0.002 & & 0.014 \\
\hline Estonia & 0.031 & $* *$ & 0.013 & -0.028 & $* *$ & 0.014 & -0.019 & $* *$ & 0.008 & 0.006 & & 0.011 \\
\hline Finland & 0.057 & $* * *$ & 0.017 & -0.009 & & 0.015 & -0.021 & $* *$ & 0.010 & -0.002 & & 0.012 \\
\hline France & 0.054 & $* * *$ & 0.015 & -0.003 & & 0.011 & -0.010 & & 0.009 & 0.026 & $* *$ & 0.012 \\
\hline Germany & 0.063 & $* * *$ & 0.012 & -0.006 & & 0.011 & -0.037 & $* * *$ & 0.013 & 0.033 & & 0.020 \\
\hline Ireland & 0.033 & $* *$ & 0.016 & -0.014 & & 0.017 & -0.010 & & 0.012 & 0.031 & & 0.021 \\
\hline Italy & 0.043 & $*$ & 0.023 & -0.053 & $* * *$ & 0.018 & 0.001 & & 0.014 & 0.046 & $* * *$ & 0.016 \\
\hline Japan & 0.081 & $* * *$ & 0.014 & -0.050 & $* *$ & 0.023 & -0.009 & & 0.007 & 0.036 & $* *$ & 0.017 \\
\hline Korea & 0.059 & $* * *$ & 0.013 & -0.039 & $* * *$ & 0.014 & -0.035 & $* * *$ & 0.011 & 0.054 & $* *$ & 0.022 \\
\hline Netherlands & 0.095 & $* * *$ & 0.021 & 0.007 & & 0.014 & -0.003 & & 0.009 & 0.009 & & 0.012 \\
\hline Norway & 0.029 & $* * *$ & 0.011 & 0.000 & & 0.012 & -0.021 & $* *$ & 0.009 & -0.035 & $* * *$ & 0.014 \\
\hline Poland & 0.055 & $* * *$ & 0.015 & -0.044 & $*$ & 0.023 & 0.004 & & 0.010 & 0.054 & $* * *$ & 0.019 \\
\hline Slovak Republic & 0.017 & & 0.015 & -0.018 & & 0.029 & -0.005 & & 0.009 & 0.010 & & 0.020 \\
\hline Spain & 0.072 & $* * *$ & 0.016 & -0.049 & $* * *$ & 0.012 & -0.062 & $* * *$ & 0.015 & 0.062 & $* * *$ & 0.023 \\
\hline Sweden & 0.036 & $*$ & 0.018 & -0.015 & & 0.018 & -0.005 & & 0.010 & 0.016 & & 0.012 \\
\hline United Kingdom & 0.052 & $* * *$ & 0.018 & -0.033 & $* * *$ & 0.012 & 0.003 & & 0.016 & 0.031 & & 0.028 \\
\hline United States & 0.035 & $* * *$ & 0.013 & 0.014 & & 0.014 & -0.018 & & 0.017 & 0.002 & & 0.025 \\
\hline Int. Avg. & 0.053 & $* * *$ & 0.004 & -0.025 & $* * *$ & 0.004 & -0.014 & $* * *$ & 0.002 & 0.022 & $* * *$ & 0.004 \\
\hline \multirow[t]{2}{*}{ Numeracy: } & \multicolumn{6}{|c|}{ underutilization } & \multicolumn{6}{|c|}{ overutilization } \\
\hline & \multicolumn{3}{|c|}{ overeducated } & \multicolumn{3}{|c|}{ undereducated } & \multicolumn{3}{|c|}{ overeducated } & \multicolumn{3}{|c|}{ undereducated } \\
\hline country & $\mathrm{B}$ & & S.E. & $\mathrm{B}$ & & S.E. & $\mathrm{B}$ & & S.E. & $\mathrm{B}$ & & S.E. \\
\hline Austria & 0.057 & $* * *$ & 0.018 & 0.007 & & 0.018 & -0.008 & & 0.010 & 0.012 & & 0.014 \\
\hline Belgium & 0.007 & & 0.020 & -0.027 & & 0.020 & 0.006 & & 0.009 & 0.010 & & 0.011 \\
\hline Canada & 0.007 & & 0.009 & -0.014 & & 0.009 & -0.007 & & 0.011 & 0.011 & & 0.014 \\
\hline Cyprus & -0.013 & & 0.019 & -0.041 & $*$ & 0.022 & 0.009 & & 0.017 & 0.076 & $* * *$ & 0.018 \\
\hline Czech Republic & 0.037 & $*$ & 0.022 & -0.008 & & 0.017 & -0.007 & & 0.015 & 0.052 & $*$ & 0.027 \\
\hline Denmark & 0.048 & $* * *$ & 0.015 & -0.011 & & 0.016 & -0.009 & & 0.008 & 0.003 & & 0.011 \\
\hline Estonia & 0.023 & $*$ & 0.012 & -0.007 & & 0.014 & -0.009 & & 0.009 & 0.016 & & 0.012 \\
\hline Finland & 0.040 & $* * *$ & 0.015 & -0.020 & & 0.014 & -0.030 & $* * *$ & 0.010 & 0.013 & & 0.012 \\
\hline France & 0.031 & $* * *$ & 0.011 & 0.018 & $*$ & 0.011 & -0.024 & $* * *$ & 0.008 & 0.020 & $* *$ & 0.010 \\
\hline Germany & 0.054 & $* * *$ & 0.016 & -0.013 & & 0.014 & -0.027 & $* * *$ & 0.010 & 0.008 & & 0.015 \\
\hline Ireland & 0.017 & & 0.013 & -0.001 & & 0.014 & -0.019 & & 0.012 & 0.004 & & 0.023 \\
\hline Italy & 0.019 & & 0.021 & -0.003 & & 0.017 & 0.014 & & 0.017 & 0.022 & & 0.018 \\
\hline Japan & 0.052 & $* * *$ & 0.014 & 0.007 & & 0.024 & -0.016 & $* *$ & 0.006 & 0.021 & & 0.017 \\
\hline Korea & 0.016 & & 0.013 & -0.008 & & 0.018 & -0.039 & $* * *$ & 0.012 & 0.012 & & 0.019 \\
\hline Netherlands & 0.104 & $* * *$ & 0.025 & 0.039 & $* *$ & 0.019 & -0.018 & $* *$ & 0.007 & -0.002 & & 0.010 \\
\hline Norway & 0.009 & & 0.017 & -0.018 & & 0.017 & -0.006 & & 0.008 & -0.005 & & 0.013 \\
\hline Poland & 0.026 & $*$ & 0.014 & -0.021 & & 0.022 & -0.036 & $* * *$ & 0.010 & 0.056 & $* * *$ & 0.020 \\
\hline Slovak Republic & 0.010 & & 0.017 & 0.008 & & 0.035 & -0.002 & & 0.010 & 0.018 & & 0.025 \\
\hline Spain & 0.023 & & 0.014 & 0.013 & & 0.015 & -0.048 & $* * *$ & 0.013 & 0.013 & & 0.021 \\
\hline Sweden & 0.035 & $*$ & 0.020 & 0.030 & & 0.019 & 0.004 & & 0.008 & 0.003 & & 0.012 \\
\hline United Kingdom & 0.010 & & 0.020 & -0.029 & $*$ & 0.017 & 0.000 & & 0.017 & 0.038 & $*$ & 0.022 \\
\hline United States & 0.020 & & 0.014 & 0.003 & & 0.013 & -0.017 & & 0.020 & -0.027 & & 0.028 \\
\hline Int. Avg. & 0.029 & $* * *$ & 0.004 & -0.004 & & 0.004 & -0.013 & $* * *$ & 0.003 & 0.017 & $* * *$ & 0.004 \\
\hline
\end{tabular}


Table A2: Effect of working in the private versus the public sector on skill mismatches, per country

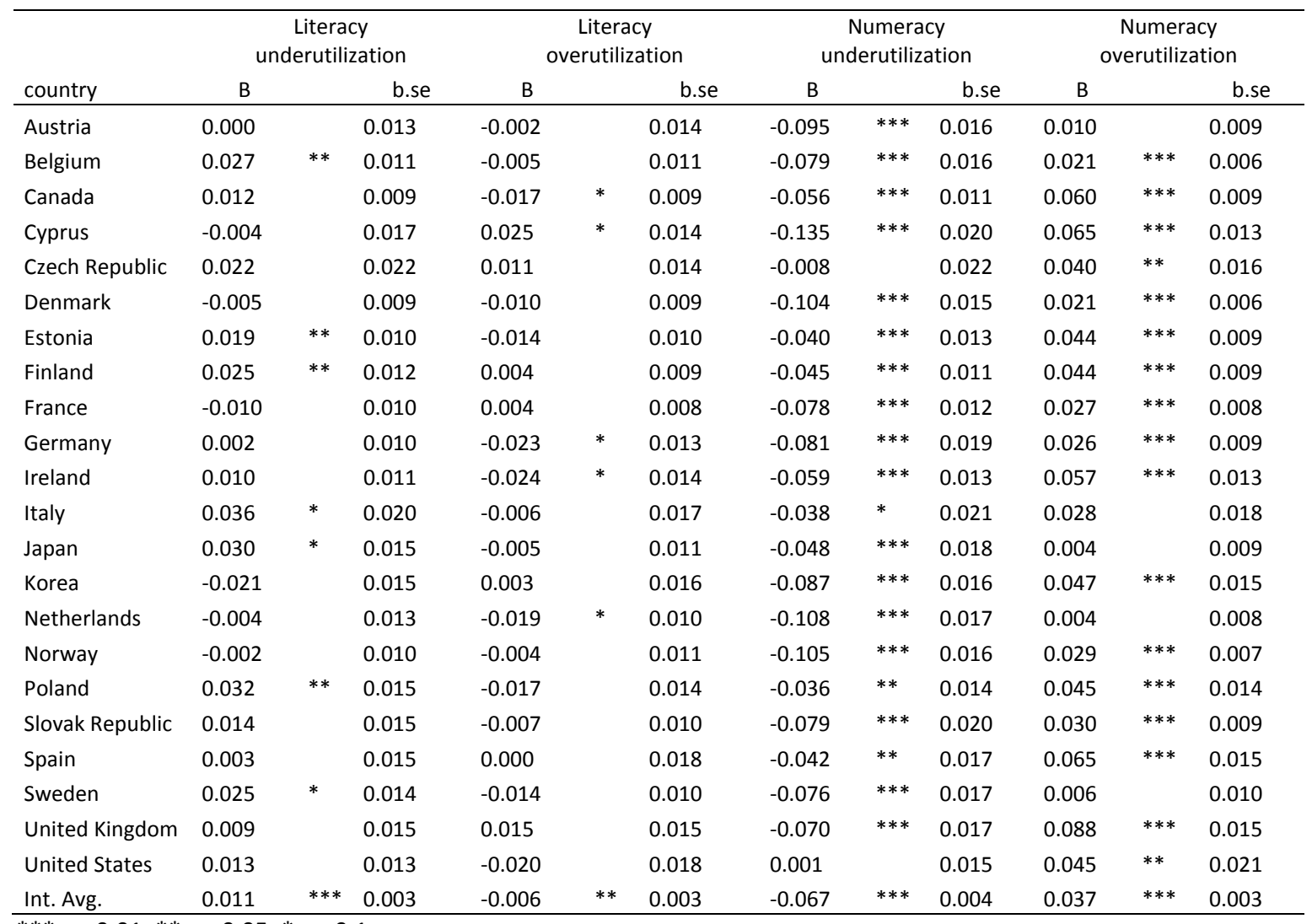

$* * *: p<0.01 ; * *: p<0.05 ; *$ : $p<0.1$ 
Table A3: Effect of firm size on skill mismatches, per country

\begin{tabular}{|c|c|c|c|c|c|c|c|c|c|c|c|c|c|c|c|c|c|c|}
\hline \multirow[b]{3}{*}{ country } & \multicolumn{9}{|c|}{ Literacy underutilization } & \multicolumn{9}{|c|}{ Literacy overutilization } \\
\hline & \multicolumn{3}{|c|}{ 11-50 employees } & \multicolumn{3}{|c|}{ 51-1000 employees } & \multicolumn{3}{|c|}{ >1000 employees } & \multicolumn{3}{|c|}{$11-50$ employees } & \multicolumn{3}{|c|}{ 51-1000 employees } & \multicolumn{3}{|c|}{$>1000$ employees } \\
\hline & B & & S.E. & B & & S.E. & B & & S.E. & B & & S.E. & B & & S.E. & B & & S.E. \\
\hline Austria & 0.011 & & 0.014 & 0.007 & & 0.013 & 0.004 & & 0.020 & -0.005 & & 0.015 & -0.019 & & 0.013 & 0.001 & & 0.023 \\
\hline Belgium & 0.040 & $* *$ & 0.016 & 0.023 & * & 0.013 & 0.041 & & 0.026 & 0.020 & & 0.012 & -0.004 & & 0.013 & -0.009 & & 0.015 \\
\hline Canada & -0.013 & & 0.011 & -0.012 & & 0.010 & 0.015 & & 0.015 & 0.022 & * & 0.012 & 0.002 & & 0.011 & -0.007 & & 0.016 \\
\hline Cyprus & -0.046 & $* * *$ & 0.018 & -0.014 & & 0.021 & -0.009 & & 0.068 & -0.014 & & 0.015 & -0.025 & & 0.016 & -0.013 & & 0.031 \\
\hline Czech Republic & -0.029 & & 0.027 & -0.059 & $* *$ & 0.029 & -0.041 & & 0.053 & -0.008 & & 0.018 & 0.003 & & 0.018 & -0.019 & & 0.030 \\
\hline Denmark & -0.002 & & 0.012 & -0.010 & & 0.010 & -0.020 & & 0.016 & 0.000 & & 0.013 & 0.000 & & 0.013 & 0.010 & & 0.020 \\
\hline Estonia & 0.009 & & 0.014 & -0.006 & & 0.013 & -0.026 & & 0.024 & -0.001 & & 0.009 & 0.009 & & 0.010 & 0.029 & & 0.030 \\
\hline Finland & -0.031 & $* *$ & 0.015 & -0.005 & & 0.016 & -0.046 & * & 0.024 & -0.001 & & 0.011 & -0.008 & & 0.011 & -0.030 & & 0.018 \\
\hline France & -0.005 & & 0.011 & 0.003 & & 0.011 & 0.033 & $*$ & 0.019 & 0.020 & $* *$ & 0.009 & 0.016 & & 0.011 & -0.009 & & 0.013 \\
\hline Germany & -0.021 & & 0.013 & -0.037 & $* * *$ & 0.012 & 0.001 & & 0.017 & 0.002 & & 0.016 & 0.004 & & 0.015 & -0.016 & & 0.020 \\
\hline Ireland & -0.038 & $* * *$ & 0.014 & -0.030 & $*$ & 0.018 & -0.015 & & 0.021 & -0.004 & & 0.015 & -0.016 & & 0.015 & -0.026 & & 0.025 \\
\hline Italy & 0.046 & $* *$ & 0.023 & 0.035 & $*$ & 0.020 & 0.029 & & 0.032 & -0.023 & & 0.018 & -0.032 & $* *$ & 0.015 & 0.009 & & 0.033 \\
\hline Japan & 0.014 & & 0.017 & -0.016 & & 0.019 & -0.018 & & 0.029 & 0.005 & & 0.008 & 0.008 & & 0.008 & 0.004 & & 0.016 \\
\hline Korea & -0.023 & * & 0.012 & -0.013 & & 0.014 & -0.041 & $* *$ & 0.016 & 0.015 & & 0.014 & -0.004 & & 0.016 & -0.016 & & 0.020 \\
\hline Netherlands & -0.024 & & 0.016 & -0.016 & & 0.015 & -0.014 & & 0.025 & 0.013 & & 0.012 & -0.001 & & 0.011 & 0.029 & & 0.020 \\
\hline Norway & 0.006 & & 0.011 & 0.002 & & 0.011 & -0.007 & & 0.015 & -0.007 & & 0.017 & -0.009 & & 0.017 & -0.001 & & 0.020 \\
\hline Poland & 0.034 & * & 0.020 & 0.023 & & 0.019 & 0.045 & & 0.031 & 0.013 & & 0.012 & 0.009 & & 0.011 & -0.023 & * & 0.012 \\
\hline Slovak Republic & 0.002 & & 0.019 & -0.008 & & 0.022 & -0.005 & & 0.034 & -0.009 & & 0.013 & -0.018 & * & 0.011 & -0.016 & & 0.021 \\
\hline Spain & -0.008 & & 0.016 & -0.002 & & 0.017 & -0.022 & & 0.023 & 0.006 & & 0.016 & -0.020 & & 0.017 & 0.049 & & 0.035 \\
\hline Sweden & -0.014 & & 0.018 & 0.007 & & 0.017 & 0.019 & & 0.028 & -0.008 & & 0.013 & -0.003 & & 0.013 & -0.013 & & 0.016 \\
\hline United Kingdom & -0.028 & & 0.020 & -0.014 & & 0.018 & -0.028 & & 0.019 & 0.026 & & 0.018 & 0.013 & & 0.017 & 0.036 & & 0.024 \\
\hline United States & -0.014 & & 0.019 & -0.028 & * & 0.016 & -0.019 & & 0.021 & 0.011 & & 0.022 & 0.035 & $* *$ & 0.017 & -0.032 & & 0.030 \\
\hline Int. Avg. & -0.006 & * & 0.004 & -0.008 & $* *$ & 0.004 & -0.006 & & 0.006 & 0.003 & & 0.003 & -0.003 & & 0.003 & -0.003 & & 0.005 \\
\hline
\end{tabular}


Table A3: Effect of firm size on skill mismatches, per country (continued)

\begin{tabular}{|c|c|c|c|c|c|c|c|c|c|c|c|c|c|c|c|c|c|c|}
\hline \multirow[b]{3}{*}{ country } & \multicolumn{9}{|c|}{ Numeracy underutilization } & \multicolumn{9}{|c|}{ Numeracy overutilization } \\
\hline & \multicolumn{3}{|c|}{ 11-50 employees } & \multicolumn{3}{|c|}{ 51-1000 employees } & \multicolumn{3}{|c|}{ >1000 employees } & \multicolumn{3}{|c|}{ 11-50 employees } & \multicolumn{3}{|c|}{ 51-1000 employees } & \multicolumn{3}{|c|}{ >1000 employees } \\
\hline & B & & S.E. & $\mathrm{B}$ & & S.E. & $\mathrm{B}$ & & S.E. & $\mathrm{B}$ & & S.E. & $\mathrm{B}$ & & S.E. & $\mathrm{B}$ & & S.E \\
\hline Austria & 0.009 & & 0.017 & 0.028 & & 0.019 & 0.034 & & 0.027 & 0.003 & & 0.011 & -0.005 & & 0.010 & -0.003 & & 0.016 \\
\hline Canada & 0.002 & & 0.011 & 0.012 & & 0.010 & 0.035 & $*$ & 0.020 & 0.013 & & 0.013 & -0.023 & $*$ & 0.012 & -0.027 & $*$ & 0.015 \\
\hline Cyprus & -0.007 & & 0.019 & -0.012 & & 0.024 & -0.079 & $*$ & 0.043 & 0.016 & & 0.016 & -0.008 & & 0.017 & -0.001 & & 0.026 \\
\hline Czech Republic & 0.033 & & 0.023 & 0.032 & & 0.023 & -0.018 & & 0.024 & 0.033 & $*$ & 0.018 & -0.005 & & 0.017 & -0.014 & & 0.033 \\
\hline Denmark & 0.005 & & 0.016 & 0.012 & & 0.015 & 0.041 & $*$ & 0.023 & -0.024 & $* *$ & 0.009 & -0.018 & $*$ & 0.010 & -0.025 & $* *$ & 0.011 \\
\hline Finland & 0.019 & & 0.012 & 0.014 & & 0.015 & 0.026 & & 0.032 & -0.016 & & 0.011 & -0.030 & $* * *$ & 0.011 & -0.060 & $* * *$ & 0.015 \\
\hline France & 0.004 & & 0.012 & 0.002 & & 0.011 & 0.050 & $* *$ & 0.025 & -0.005 & & 0.011 & -0.001 & & 0.011 & -0.018 & & 0.015 \\
\hline Germany & 0.015 & & 0.013 & 0.011 & & 0.014 & 0.056 & $* *$ & 0.023 & -0.028 & * & 0.016 & -0.047 & $* * *$ & 0.015 & -0.050 & $* * *$ & 0.017 \\
\hline Ireland & -0.007 & & 0.012 & 0.026 & $*$ & 0.015 & 0.033 & & 0.025 & 0.027 & & 0.017 & 0.005 & & 0.013 & 0.011 & & 0.020 \\
\hline Italy & 0.020 & & 0.019 & 0.017 & & 0.021 & 0.050 & & 0.036 & -0.044 & $* * *$ & 0.017 & -0.046 & $* * *$ & 0.014 & 0.013 & & 0.037 \\
\hline Japan & 0.051 & $* * *$ & 0.014 & 0.034 & $* *$ & 0.015 & 0.102 & $* * *$ & 0.029 & -0.002 & & 0.008 & 0.001 & & 0.009 & -0.024 & $* * *$ & 0.008 \\
\hline Korea & 0.002 & & 0.013 & 0.013 & & 0.014 & -0.004 & & 0.020 & 0.011 & & 0.013 & 0.008 & & 0.015 & 0.012 & & 0.024 \\
\hline Netherlands & 0.040 & $* *$ & 0.018 & 0.061 & $* * *$ & 0.019 & 0.037 & & 0.028 & -0.013 & & 0.010 & -0.010 & & 0.011 & -0.010 & & 0.015 \\
\hline Poland & 0.020 & & 0.015 & 0.013 & & 0.017 & 0.023 & & 0.025 & -0.021 & & 0.016 & -0.022 & & 0.014 & -0.067 & $* * *$ & 0.015 \\
\hline Slovak Republic & -0.004 & & 0.019 & 0.013 & & 0.018 & 0.066 & $* *$ & 0.033 & 0.008 & & 0.011 & -0.003 & & 0.011 & 0.015 & & 0.021 \\
\hline Spain & -0.002 & & 0.013 & 0.026 & $*$ & 0.014 & 0.077 & $* *$ & 0.038 & -0.016 & & 0.017 & -0.019 & & 0.015 & -0.011 & & 0.029 \\
\hline Sweden & 0.022 & & 0.022 & 0.004 & & 0.019 & 0.066 & $* *$ & 0.030 & -0.013 & & 0.011 & -0.006 & & 0.012 & -0.005 & & 0.015 \\
\hline United Kingdom & -0.023 & & 0.017 & -0.008 & & 0.018 & -0.008 & & 0.027 & 0.040 & $* *$ & 0.018 & 0.043 & $* * *$ & 0.016 & 0.064 & $* * *$ & 0.020 \\
\hline United States & 0.006 & & 0.019 & 0.006 & & 0.015 & 0.014 & & 0.023 & -0.024 & & 0.026 & -0.014 & & 0.025 & -0.046 & & 0.031 \\
\hline Int. Avg. & 0.013 & $* * *$ & 0.004 & 0.020 & $* * *$ & 0.004 & 0.038 & $* * *$ & 0.006 & -0.002 & & 0.003 & -0.010 & $* * *$ & 0.003 & -0.011 & $* *$ & 0.005 \\
\hline
\end{tabular}


Table A4: Effect of age on skill mismatches, per country

\begin{tabular}{|c|c|c|c|c|c|c|c|c|c|c|c|c|}
\hline \multirow[b]{3}{*}{ country } & \multicolumn{6}{|c|}{ Literacy underutilization } & \multicolumn{6}{|c|}{ Literacy overutilization } \\
\hline & \multicolumn{3}{|c|}{ Age } & \multicolumn{3}{|c|}{ Age-sqared (X100) } & \multicolumn{3}{|c|}{ Age } & \multicolumn{3}{|c|}{ Age-sqared (X100) } \\
\hline & $\mathrm{B}$ & & S.E. & $\mathrm{B}$ & & S.E. & $\mathrm{B}$ & & S.E. & $\mathrm{B}$ & & S.E. \\
\hline Austria & -0.006 & $*$ & 0.003 & 0.007 & & 0.004 & -0.005 & & 0.003 & 0.009 & $* *$ & 0.005 \\
\hline Belgium & -0.001 & & 0.003 & -0.002 & & 0.004 & -0.002 & & 0.003 & 0.004 & & 0.004 \\
\hline Canada & -0.009 & $* * *$ & 0.002 & 0.009 & $* * *$ & 0.002 & 0.002 & & 0.002 & 0.000 & & 0.003 \\
\hline Cyprus & -0.007 & & 0.006 & 0.009 & & 0.007 & 0.001 & & 0.005 & -0.001 & & 0.006 \\
\hline Czech Republic & -0.007 & & 0.007 & 0.008 & & 0.009 & -0.001 & & 0.004 & 0.002 & & 0.005 \\
\hline Denmark & -0.014 & $* * *$ & 0.003 & 0.013 & $* * *$ & 0.004 & 0.002 & & 0.003 & -0.001 & & 0.003 \\
\hline Estonia & -0.012 & $* * *$ & 0.004 & 0.015 & $* * *$ & 0.004 & 0.004 & $*$ & 0.002 & -0.003 & & 0.003 \\
\hline Finland & -0.013 & $* * *$ & 0.004 & 0.010 & $* *$ & 0.004 & -0.007 & $* * *$ & 0.002 & 0.010 & $* * *$ & 0.003 \\
\hline France & -0.009 & $* * *$ & 0.003 & 0.009 & $* * *$ & 0.003 & 0.004 & $*$ & 0.002 & -0.002 & & 0.003 \\
\hline Germany & 0.001 & & 0.003 & -0.001 & & 0.004 & -0.003 & & 0.004 & 0.005 & & 0.004 \\
\hline Ireland & -0.020 & $* * *$ & 0.005 & 0.023 & $* * *$ & 0.006 & 0.011 & $* * *$ & 0.004 & -0.012 & $* * *$ & 0.005 \\
\hline Italy & -0.003 & & 0.004 & 0.005 & & 0.006 & -0.003 & & 0.005 & 0.005 & & 0.006 \\
\hline Japan & -0.002 & & 0.004 & 0.000 & & 0.005 & 0.000 & & 0.002 & 0.002 & & 0.002 \\
\hline Korea & -0.015 & $* * *$ & 0.004 & 0.015 & $* * *$ & 0.005 & 0.007 & $* *$ & 0.003 & -0.006 & & 0.004 \\
\hline Netherlands & -0.016 & $* * *$ & 0.004 & 0.015 & $* * *$ & 0.004 & 0.000 & & 0.002 & 0.002 & & 0.002 \\
\hline Norway & -0.002 & & 0.002 & 0.000 & & 0.003 & -0.003 & & 0.003 & 0.005 & & 0.003 \\
\hline Poland & -0.020 & $* * *$ & 0.005 & 0.024 & $* * *$ & 0.006 & 0.005 & $* *$ & 0.002 & -0.006 & $* *$ & 0.003 \\
\hline Slovak Republic & -0.002 & & 0.006 & 0.000 & & 0.007 & -0.001 & & 0.003 & 0.002 & & 0.003 \\
\hline Spain & -0.003 & & 0.004 & 0.002 & & 0.005 & -0.004 & & 0.004 & 0.009 & $*$ & 0.005 \\
\hline Sweden & -0.005 & & 0.004 & 0.002 & & 0.004 & 0.003 & & 0.002 & -0.003 & & 0.003 \\
\hline United Kingdom & -0.011 & $* *$ & 0.004 & 0.012 & $* *$ & 0.005 & 0.004 & & 0.003 & -0.003 & & 0.004 \\
\hline United States & -0.008 & $* * *$ & 0.002 & 0.007 & $* *$ & 0.003 & 0.004 & & 0.005 & -0.002 & & 0.006 \\
\hline \multirow[t]{3}{*}{ Int. Avg. } & -0.008 & $* * *$ & 0.001 & 0.008 & $* * *$ & 0.001 & 0.001 & & 0.001 & 0.001 & & 0.001 \\
\hline & \multicolumn{6}{|c|}{ Numeracy underutilization } & \multicolumn{6}{|c|}{ Numeracy overutilization } \\
\hline & \multicolumn{3}{|c|}{ Age } & \multicolumn{3}{|c|}{ Age-sqared (X100) } & \multicolumn{3}{|c|}{ Age } & \multicolumn{3}{|c|}{ Age-sqared (X100) } \\
\hline country & B & & S.E. & $\mathrm{B}$ & & S.E. & B & & S.E. & $\mathrm{B}$ & & S.E. \\
\hline Austria & 0.001 & & 0.004 & -0.002 & & 0.005 & -0.001 & & 0.003 & 0.001 & & 0.004 \\
\hline Belgium & 0.013 & $* *$ & 0.005 & -0.018 & $* * *$ & 0.006 & -0.004 & & 0.002 & 0.005 & $*$ & 0.003 \\
\hline Canada & -0.004 & $* *$ & 0.002 & 0.003 & & 0.002 & 0.002 & & 0.002 & -0.001 & & 0.003 \\
\hline Cyprus & 0.000 & & 0.006 & 0.000 & & 0.007 & 0.001 & & 0.005 & -0.002 & & 0.006 \\
\hline Czech Republic & 0.000 & & 0.006 & 0.000 & & 0.007 & 0.001 & & 0.004 & -0.002 & & 0.005 \\
\hline Denmark & 0.001 & & 0.004 & -0.004 & & 0.005 & 0.000 & & 0.002 & 0.001 & & 0.002 \\
\hline Estonia & -0.005 & $*$ & 0.003 & 0.006 & $*$ & 0.003 & 0.006 & $* * *$ & 0.002 & -0.006 & $* * *$ & 0.002 \\
\hline Finland & -0.006 & & 0.004 & 0.004 & & 0.005 & 0.001 & & 0.003 & 0.001 & & 0.004 \\
\hline France & -0.005 & $*$ & 0.003 & 0.004 & & 0.003 & -0.002 & & 0.003 & 0.002 & & 0.003 \\
\hline Germany & 0.000 & & 0.004 & -0.002 & & 0.004 & 0.000 & & 0.003 & 0.001 & & 0.004 \\
\hline Ireland & -0.001 & & 0.004 & 0.000 & & 0.004 & 0.004 & & 0.003 & -0.004 & & 0.004 \\
\hline Italy & 0.004 & & 0.005 & -0.006 & & 0.006 & -0.001 & & 0.005 & 0.001 & & 0.006 \\
\hline Japan & -0.002 & & 0.004 & 0.001 & & 0.005 & 0.001 & & 0.002 & -0.001 & & 0.002 \\
\hline Korea & -0.011 & $* * *$ & 0.003 & 0.012 & $* * *$ & 0.004 & 0.006 & $*$ & 0.003 & -0.007 & $*$ & 0.004 \\
\hline Netherlands & -0.005 & & 0.005 & 0.004 & & 0.005 & 0.000 & & 0.002 & -0.001 & & 0.002 \\
\hline Norway & 0.001 & & 0.003 & -0.005 & & 0.004 & -0.003 & & 0.003 & 0.003 & & 0.003 \\
\hline Poland & -0.004 & & 0.004 & 0.005 & & 0.005 & 0.002 & & 0.003 & -0.003 & & 0.003 \\
\hline Slovak Republic & -0.008 & & 0.005 & 0.008 & & 0.006 & 0.001 & & 0.003 & -0.001 & & 0.004 \\
\hline Spain & 0.003 & & 0.004 & -0.006 & & 0.005 & -0.004 & & 0.004 & 0.006 & & 0.004 \\
\hline Sweden & -0.002 & & 0.004 & -0.002 & & 0.005 & 0.006 & $* * *$ & 0.002 & -0.006 & $* * *$ & 0.002 \\
\hline United Kingdom & 0.004 & & 0.004 & -0.005 & & 0.005 & 0.003 & & 0.004 & -0.004 & & 0.004 \\
\hline United States & -0.004 & & 0.003 & 0.003 & & 0.004 & -0.001 & & 0.004 & 0.001 & & 0.005 \\
\hline Int. Avg. & -0.001 & & 0.001 & 0.000 & & 0.001 & 0.001 & & 0.001 & -0.001 & & 0.001 \\
\hline
\end{tabular}

***: $p<0.01 ; * *: p<0.05 ; *: p<0.1$ 
Table A5: Effect of occupational level on skill mismatches, per country

\begin{tabular}{|c|c|c|c|c|c|c|c|c|c|c|c|c|c|c|c|c|c|c|}
\hline \multirow[b]{3}{*}{ country } & \multicolumn{9}{|c|}{$\begin{array}{c}\text { Literacy } \\
\text { underutilization }\end{array}$} & \multicolumn{9}{|c|}{$\begin{array}{c}\text { Literacy } \\
\text { overutilization }\end{array}$} \\
\hline & \multicolumn{3}{|c|}{ skilled professionals } & \multicolumn{3}{|c|}{ semi-skilled blue-collar } & \multicolumn{3}{|c|}{ elementary occupations } & \multicolumn{3}{|c|}{ skilled professionals } & \multicolumn{3}{|c|}{ semi-skilled blue-collar } & \multicolumn{3}{|c|}{ elementary occupations } \\
\hline & B & & S.E. & B & & S.E. & B & & S.E. & B & & S.E. & $\mathrm{B}$ & & S.E. & B & & S.E. \\
\hline Austria & -0.022 & & 0.014 & 0.034 & * & 0.020 & 0.035 & & 0.030 & 0.001 & & 0.017 & -0.043 & $* * *$ & 0.016 & -0.060 & $* * *$ & 0.019 \\
\hline Belgium & -0.046 & $* * *$ & 0.014 & 0.021 & & 0.022 & 0.046 & $*$ & 0.023 & 0.029 & $* *$ & 0.012 & -0.031 & ** & 0.013 & -0.018 & & 0.018 \\
\hline Canada & -0.028 & $* * *$ & 0.011 & 0.008 & & 0.014 & 0.044 & $* *$ & 0.020 & 0.034 & $* * *$ & 0.010 & 0.032 & $* *$ & 0.015 & -0.043 & $* * *$ & 0.013 \\
\hline Cyprus & -0.029 & & 0.023 & 0.040 & & 0.029 & 0.211 & $* * *$ & 0.055 & 0.007 & & 0.017 & -0.056 & $* * *$ & 0.021 & -0.037 & $*$ & 0.020 \\
\hline Czech Republic & -0.053 & $* *$ & 0.025 & 0.048 & & 0.034 & 0.067 & & 0.064 & 0.020 & & 0.024 & -0.064 & $* * *$ & 0.018 & -0.054 & $* * *$ & 0.014 \\
\hline Denmark & -0.007 & & 0.011 & 0.020 & & 0.017 & 0.074 & $* * *$ & 0.025 & 0.024 & * & 0.013 & 0.006 & & 0.017 & -0.020 & & 0.021 \\
\hline Estonia & -0.088 & $* * *$ & 0.015 & 0.049 & $* *$ & 0.019 & 0.201 & $* * *$ & 0.028 & 0.009 & & 0.011 & -0.024 & * & 0.012 & -0.062 & $* * *$ & 0.011 \\
\hline Finland & 0.002 & & 0.014 & 0.083 & $* * *$ & 0.016 & 0.100 & $* * *$ & 0.035 & 0.005 & & 0.012 & -0.010 & & 0.012 & 0.000 & & 0.020 \\
\hline France & -0.046 & $* * *$ & 0.013 & 0.030 & $*$ & 0.016 & 0.078 & $* * *$ & 0.021 & 0.018 & $*$ & 0.011 & -0.026 & $*$ & 0.014 & -0.016 & & 0.016 \\
\hline Germany & -0.014 & & 0.011 & 0.016 & & 0.014 & 0.130 & $* * *$ & 0.027 & -0.040 & $* * *$ & 0.015 & -0.062 & $* * *$ & 0.020 & -0.117 & $* * *$ & 0.019 \\
\hline Ireland & -0.070 & $* * *$ & 0.016 & -0.027 & & 0.021 & 0.040 & & 0.031 & 0.030 & $*$ & 0.017 & 0.000 & & 0.021 & -0.026 & & 0.021 \\
\hline Italy & -0.047 & $* * *$ & 0.017 & 0.042 & & 0.029 & -0.005 & & 0.029 & 0.074 & $* * *$ & 0.021 & -0.008 & & 0.015 & -0.007 & & 0.016 \\
\hline Japan & -0.065 & $* * *$ & 0.017 & 0.118 & $* * *$ & 0.021 & 0.214 & $* * *$ & 0.037 & 0.001 & & 0.009 & -0.019 & $*$ & 0.011 & -0.013 & & 0.014 \\
\hline Korea & 0.001 & & 0.013 & 0.044 & $* *$ & 0.017 & 0.061 & $* *$ & 0.024 & -0.022 & & 0.016 & -0.039 & $* *$ & 0.015 & -0.049 & $* * *$ & 0.018 \\
\hline Netherlands & -0.021 & & 0.016 & 0.019 & & 0.024 & 0.089 & $* *$ & 0.038 & 0.025 & $* *$ & 0.011 & 0.000 & & 0.014 & -0.041 & $* *$ & 0.017 \\
\hline Norway & -0.002 & & 0.011 & 0.004 & & 0.017 & 0.011 & & 0.026 & 0.003 & & 0.013 & 0.026 & & 0.021 & 0.000 & & 0.038 \\
\hline Poland & -0.027 & & 0.018 & 0.109 & $* * *$ & 0.025 & 0.171 & $* * *$ & 0.046 & -0.012 & & 0.016 & -0.015 & & 0.016 & -0.042 & $* *$ & 0.016 \\
\hline Slovak Republic & -0.107 & $* * *$ & 0.017 & 0.089 & $* * *$ & 0.026 & 0.113 & $* * *$ & 0.042 & 0.034 & $* *$ & 0.014 & -0.006 & & 0.011 & -0.010 & & 0.012 \\
\hline Spain & -0.003 & & 0.016 & 0.032 & & 0.022 & 0.060 & $* *$ & 0.024 & -0.022 & & 0.018 & -0.028 & & 0.019 & -0.055 & $* * *$ & 0.016 \\
\hline Sweden & -0.036 & $* *$ & 0.016 & 0.080 & $* * *$ & 0.025 & 0.177 & $* * *$ & 0.050 & 0.031 & $*$ & 0.017 & -0.006 & & 0.013 & 0.010 & & 0.029 \\
\hline United Kingdom & -0.018 & & 0.017 & 0.007 & & 0.024 & 0.027 & & 0.028 & -0.006 & & 0.016 & -0.021 & & 0.022 & -0.063 & $* * *$ & 0.023 \\
\hline United States & -0.044 & $* * *$ & 0.014 & -0.017 & & 0.013 & 0.109 & $* * *$ & 0.031 & 0.013 & & 0.023 & -0.065 & ** & 0.027 & -0.092 & $* * *$ & 0.031 \\
\hline Int. Avg. & -0.035 & $* * *$ & 0.003 & 0.039 & $* * *$ & 0.005 & 0.093 & $* * *$ & 0.008 & 0.012 & $* * *$ & 0.003 & -0.021 & $* * *$ & 0.004 & -0.037 & $* * *$ & 0.004 \\
\hline
\end{tabular}


Table A5: Effect of occupational level on skill mismatches, per country (continued)

\begin{tabular}{|c|c|c|c|c|c|c|c|c|c|c|c|c|c|c|c|c|c|}
\hline \multirow[b]{3}{*}{ country } & \multicolumn{9}{|c|}{$\begin{array}{c}\text { Numeracy } \\
\text { underutilization }\end{array}$} & \multicolumn{8}{|c|}{$\begin{array}{c}\text { Numeracy } \\
\text { overutilization }\end{array}$} \\
\hline & \multicolumn{3}{|c|}{ skilled professionals } & \multicolumn{3}{|c|}{ semi-skilled blue-collar } & \multicolumn{3}{|c|}{ elementary occupations } & \multicolumn{3}{|c|}{ skilled professionals } & \multicolumn{3}{|c|}{ semi-skilled blue-collar } & \multicolumn{2}{|c|}{ elementary occupations } \\
\hline & B & & S.E. & B & & S.E. & B & & S.E. & B & & S.E. & B & & S.E. & B & S.E. \\
\hline Austria & -0.003 & & 0.019 & 0.045 & $* *$ & 0.021 & -0.011 & & 0.025 & 0.008 & & 0.013 & -0.010 & & 0.014 & -0.008 & 0.020 \\
\hline Belgium & -0.046 & $* *$ & 0.022 & 0.070 & $* * *$ & 0.026 & 0.013 & & 0.030 & 0.032 & $* * *$ & 0.010 & -0.022 & $* *$ & 0.009 & -0.011 & 0.012 \\
\hline Canada & -0.009 & & 0.009 & 0.055 & $* * *$ & 0.015 & 0.052 & $* *$ & 0.021 & 0.034 & $* * *$ & 0.012 & -0.042 & $* * *$ & 0.016 & -0.083 & 0.016 \\
\hline Cyprus & 0.005 & & 0.024 & 0.050 & $*$ & 0.028 & 0.030 & & 0.032 & -0.018 & & 0.018 & -0.021 & & 0.025 & -0.018 & 0.029 \\
\hline Czech Republic & -0.012 & & 0.021 & 0.006 & & 0.029 & 0.072 & & 0.053 & 0.041 & $*$ & 0.023 & -0.042 & $* *$ & 0.017 & -0.046 & 0.029 \\
\hline Denmark & -0.012 & & 0.017 & 0.032 & & 0.021 & 0.044 & $*$ & 0.025 & 0.003 & & 0.008 & -0.021 & $*$ & 0.012 & -0.014 & 0.015 \\
\hline Estonia & -0.054 & $* * *$ & 0.014 & -0.003 & & 0.015 & 0.094 & $* * *$ & 0.023 & -0.002 & & 0.012 & -0.052 & $* * *$ & 0.014 & -0.073 & 0.013 \\
\hline Finland & 0.026 & & 0.016 & 0.063 & $* * *$ & 0.019 & -0.006 & & 0.022 & -0.013 & & 0.013 & -0.038 & $* * *$ & 0.013 & -0.003 & 0.021 \\
\hline France & -0.008 & & 0.012 & 0.024 & $*$ & 0.014 & 0.017 & & 0.014 & 0.012 & & 0.012 & -0.023 & $*$ & 0.013 & -0.019 & 0.013 \\
\hline Germany & 0.000 & & 0.014 & 0.050 & $* * *$ & 0.019 & 0.085 & $* * *$ & 0.028 & -0.030 & $* *$ & 0.013 & -0.082 & $* * *$ & 0.017 & -0.101 & 0.019 \\
\hline Ireland & -0.049 & $* * *$ & 0.017 & 0.011 & & 0.018 & 0.013 & & 0.026 & 0.024 & & 0.015 & -0.005 & & 0.019 & -0.045 & 0.020 \\
\hline Italy & -0.050 & $* *$ & 0.023 & 0.039 & $*$ & 0.024 & 0.007 & & 0.026 & 0.069 & $* * *$ & 0.019 & -0.034 & * & 0.018 & -0.033 & 0.018 \\
\hline Japan & -0.025 & & 0.018 & 0.024 & & 0.020 & 0.090 & $* * *$ & 0.034 & -0.001 & & 0.009 & 0.007 & & 0.010 & -0.022 & 0.007 \\
\hline Korea & 0.017 & & 0.014 & 0.048 & $* * *$ & 0.017 & 0.050 & $* * *$ & 0.019 & -0.071 & $* * *$ & 0.014 & -0.075 & $* * *$ & 0.018 & -0.047 & 0.018 \\
\hline Netherlands & -0.006 & & 0.020 & 0.076 & $* *$ & 0.031 & 0.022 & & 0.033 & 0.008 & & 0.010 & -0.014 & & 0.011 & -0.022 & 0.013 \\
\hline Norway & -0.020 & & 0.018 & 0.041 & $* *$ & 0.020 & -0.006 & & 0.034 & 0.010 & & 0.012 & -0.002 & & 0.016 & 0.044 & 0.035 \\
\hline Poland & 0.002 & & 0.019 & 0.029 & & 0.022 & 0.047 & & 0.034 & -0.018 & & 0.018 & -0.049 & $* * *$ & 0.016 & -0.061 & 0.019 \\
\hline Slovak Republic & -0.014 & & 0.015 & 0.144 & $* * *$ & 0.021 & 0.114 & $* * *$ & 0.033 & 0.025 & $*$ & 0.015 & -0.046 & $* * *$ & 0.012 & -0.037 & 0.017 \\
\hline Spain & 0.001 & & 0.016 & -0.008 & & 0.015 & 0.056 & $* * *$ & 0.021 & -0.006 & & 0.019 & -0.058 & $* * *$ & 0.020 & -0.070 & 0.015 \\
\hline Sweden & -0.051 & $* *$ & 0.021 & 0.065 & $* *$ & 0.026 & 0.093 & $*$ & 0.048 & 0.032 & $* *$ & 0.014 & -0.016 & & 0.011 & 0.019 & 0.027 \\
\hline United Kingdom & -0.029 & $*$ & 0.015 & 0.064 & $* *$ & 0.025 & 0.007 & & 0.024 & 0.020 & & 0.018 & -0.039 & $* *$ & 0.019 & -0.015 & 0.028 \\
\hline United States & -0.019 & & 0.017 & 0.003 & & 0.020 & 0.031 & & 0.030 & 0.004 & & 0.022 & -0.084 & $* * *$ & 0.029 & -0.177 & 0.036 \\
\hline Int. Avg. & -0.016 & $* * *$ & 0.004 & 0.042 & $* * *$ & 0.005 & 0.042 & $* * *$ & 0.006 & 0.007 & $* *$ & 0.003 & -0.035 & $* * *$ & 0.004 & -0.038 & 0.005 \\
\hline
\end{tabular}


Table A6: Effect of having a VET versus a non-VET secondary qualification as highest completed education on skill mismatches, per country

\begin{tabular}{|c|c|c|c|c|c|c|c|c|c|c|c|c|}
\hline \multirow[b]{2}{*}{ Country } & \multicolumn{3}{|c|}{$\begin{array}{c}\text { Literacy } \\
\text { underutilization }\end{array}$} & \multicolumn{3}{|c|}{$\begin{array}{c}\text { Literacy } \\
\text { overutilization }\end{array}$} & \multicolumn{3}{|c|}{$\begin{array}{c}\text { Numeracy } \\
\text { underutilization }\end{array}$} & \multicolumn{3}{|c|}{$\begin{array}{c}\text { Numeracy } \\
\text { overutilization }\end{array}$} \\
\hline & $\mathrm{B}$ & & S.E & $\mathrm{B}$ & & S.E & $\mathrm{B}$ & & S.E & $\mathrm{B}$ & & S.E \\
\hline Austria & -0.110 & $* * *$ & 0.038 & 0.061 & $* * *$ & 0.021 & -0.117 & $* *$ & 0.047 & 0.023 & $*$ & 0.013 \\
\hline Canada & -0.005 & & 0.028 & -0.037 & & 0.047 & 0.016 & & 0.021 & -0.031 & & 0.045 \\
\hline Czech Republic & -0.031 & & 0.037 & 0.056 & $* *$ & 0.024 & 0.002 & & 0.026 & -0.045 & & 0.051 \\
\hline Denmark & -0.048 & $* *$ & 0.022 & 0.066 & $* * *$ & 0.016 & -0.067 & $* *$ & 0.029 & 0.016 & & 0.012 \\
\hline Estonia & -0.011 & & 0.017 & 0.007 & & 0.011 & -0.015 & & 0.016 & 0.024 & $*$ & 0.012 \\
\hline Finland & -0.074 & $* *$ & 0.035 & 0.031 & $* *$ & 0.016 & -0.040 & & 0.025 & 0.022 & & 0.020 \\
\hline France & -0.113 & $* * *$ & 0.027 & 0.054 & $* * *$ & 0.017 & -0.071 & $* * *$ & 0.024 & 0.030 & $*$ & 0.018 \\
\hline Germany & -0.144 & $* *$ & 0.072 & 0.042 & & 0.035 & -0.135 & $* *$ & 0.061 & 0.050 & $* * *$ & 0.017 \\
\hline Ireland & -0.074 & $* * *$ & 0.021 & 0.041 & $* *$ & 0.020 & -0.016 & & 0.018 & 0.029 & & 0.020 \\
\hline Japan & -0.028 & & 0.029 & 0.030 & $*$ & 0.018 & 0.014 & & 0.022 & -0.014 & & 0.012 \\
\hline Korea & -0.015 & & 0.022 & -0.004 & & 0.020 & -0.012 & & 0.018 & -0.002 & & 0.018 \\
\hline Netherlands & -0.172 & $* * *$ & 0.027 & 0.057 & $* * *$ & 0.018 & -0.133 & $* * *$ & 0.030 & 0.020 & $*$ & 0.010 \\
\hline Norway & -0.040 & $* *$ & 0.019 & 0.002 & & 0.018 & -0.044 & $* *$ & 0.021 & -0.004 & & 0.016 \\
\hline Poland & -0.051 & & 0.033 & 0.021 & & 0.014 & -0.052 & $*$ & 0.032 & 0.018 & & 0.020 \\
\hline Slovak Republic & 0.012 & & 0.023 & -0.020 & $* *$ & 0.010 & 0.009 & & 0.023 & -0.005 & & 0.011 \\
\hline Spain & -0.068 & $* *$ & 0.029 & 0.032 & & 0.044 & -0.047 & & 0.031 & -0.016 & & 0.033 \\
\hline Sweden & 0.011 & & 0.023 & 0.027 & $*$ & 0.015 & -0.023 & & 0.024 & -0.017 & & 0.011 \\
\hline United Kingdom & 0.031 & & 0.035 & 0.056 & $* *$ & 0.028 & 0.006 & & 0.029 & 0.043 & $*$ & 0.024 \\
\hline United States & 0.004 & & 0.024 & 0.047 & & 0.037 & 0.022 & & 0.023 & -0.053 & & 0.039 \\
\hline Int. Avg. & -0.049 & $* * *$ & 0.007 & 0.030 & $* * *$ & 0.006 & -0.037 & $* * *$ & 0.007 & 0.005 & & 0.006 \\
\hline
\end{tabular}

